\title{
Economics
}

The Open-Access, Open-Assessment E-Journal

Vol. 13, 2019-47 | November 28, 2019 | http://dx.doi.org/10.5018/economics-ejournal.ja.2019-47

\section{Can reducing carbon emissions improve economic performance - evidence from China}

Fei Yang, Beibei Shi, Ming Xu, and Chen Feng

\begin{abstract}
As the problem of carbon emissions is becoming increasingly more serious around the world, how to balance carbon emissions reduction and economic growth has become an important issue in the field of environmental economics. China is the world's largest carbon dioxide emitter, and China's Low-Carbon Pilot (CLCP) policy has significantly reduced carbon dioxide emissions and achieved expected benefits. However, is environmental quality improving at the expense of economic growth? This article selects macro panel data of 286 Chinese prefecturelevel cities and micro data of Chinese industrial enterprises from 2001 to 2013, takes the CLCP policy implementation by five provinces and eight cities as a quasi-natural experiment, uses difference-in-differences (DID) method to investigate the causal effect of CLCP policy on regional economic growth and enterprise behavior. The results are as follows. First, the CLCP policy significantly promotes regional economic growth. Moreover, as the implementation time of the policy continues, environmental regulation has a greater effect of promoting economic growth. Second, although the CLCP policy significantly increases various production costs, it also promotes the growth of enterprises' output and benefits. Third, under the pressure of enterprise cost increase caused by environmental regulation, enterprises choose the positive way of strengthening internal management, improving efficiency and increasing innovation instead of choosing the negative way of trans-regional transfer, and finally achieve an improvement in output and benefits.
\end{abstract}

JEL O12 O13 Q38

Keywords CLCP policy; economic growth; behavior of enterprise; DID

\section{Authors}

Fei Yang, Northwest University of Political Science and Law, Shaanxi, China

Beibei Shi, Northwest University, Shaanxi, China, shibeibei@stumail.nwu.edu.cn

Ming $X u$, Chinese Academy of Social Sciences, Beijing, China

Chen Feng, Shanghai University of Finance and Economics, Shanghai, China

Citation Fei Yang, Beibei Shi, Ming Xu, and Chen Feng (2019). Can reducing carbon emissions improve economic performance - evidence from China. Economics: The OpenAccess, Open-Assessment E-Journal, 13 (2019-47): 1-39.

http://dx.doi.org/10.5018/economics-ejournal.ja.2019-47

Received December 12, 2018 Published as Economics Discussion Paper February 12, 2019 Revised October 21, 2019 Accepted November 18, 2019 Published November 28, 2019

(c) Author(s) 2019. Licensed under the Creative Commons License - Attribution 4.0 International (CC BY 4.0) 


\section{Introduction}

With the continuous expansion of human activities, climate change and environmental conditions are greatly affected, which has become an important issue that restricts human survival and further development. This is especially true in China where the economy is growing fast. According to the World Bank, 16 of the 20 most polluted cities in the world are in China, and 58\% of Chinese cities have an average PM10 concentration in the atmosphere of more than 100 micrograms per cubic meter; meanwhile, only $1 \%$ of China's urban population is in areas where the average annual PM10 concentration is less than 40 micrograms per cubic meter (Wang and Huang, 2015). Severe air pollution has not only a negative impact on economic growth, but also a significant influence on the safety of human life. Statistically, twothirds of the 338 Chinese cities with air quality monitoring are polluted, and two-thirds of them are rated as moderate or severe. In addition, China scored 65.1 in the World Environmental Performance Ranking in 2016, which was jointly released by the Yale University and Columbia University, and ranked 109th out of 180 countries and regions, which means that China's environmental performance is at the bottom of all countries and regions. Among all the gas emissions, the global warming caused by $\mathrm{CO} 2$ emissions is one of the current social concerns and urgent problems. Faced with massive emissions of greenhouse gases and the increasingly obvious trend of global warming, many countries have actively issued countermeasures through regulation to attempt to curb the increasingly serious environmental deterioration. Among these countries, the European Union was the first to put forward the famous "The EU Emission Trading System” (EU ETS), which restricts enterprises' carbon emissions behavior by pricing pollution emissions and requiring them to buy carbon emission quotas. EU ETS implementation has attracted collective attention of various countries and regions and achieved success to some extent.

At the same time, China's environmental problems, such as climate change and greenhouse gas emissions, attracts attention not only from the Chinese people but also from people in other parts of the world. Currently, China has become the world's largest carbon emitter, and its emissions are in urgent need to be solved. In this regard, in 2009, Chinese government first announced a clear and quantifiable target for controlling greenhouse gas emissions, which is that China will reduce CO2 emissions per unit of GDP by 40-50\% from 2005 levels by the year 2020. To achieve this goal, the National Development and Reform Commission of China (NDRC) issued "the notice of the national development and reform commission on the pilot work of low-carbon provinces and cities” on 19 July 2010 (hereinafter referred to as China's Low-Carbon Pilot policy, namely, CLCP policy). Five provinces (Guangdong, Hubei, Liaoning, Shaanxi and Yunnan) and eight cities (Chongqing, Tianjin, Shenzhen, Xiamen, Hangzhou, Guiyang, Nanchang and Baoding) were selected to be the pilot areas.

It is undeniable that CLCP policy implementation is a difficult step for the Chinese government to carry out carbon emission governance. Through the policy implementation, the Chinese government attempts to explore a beneficial governance path to further reduce carbon emissions, improve environmental quality and transform the extensive development mode of China's economy that features high energy consumption, pollution and emissions to thoroughly realize a green and clean development mode. This policy is an important tool of environmental regulation for China. Since policy implementation, a large number of studies have been con- 
ducted, such as, policy implementation, the planning of the development path, carbon emission measurement and so on (Xue et al., 2012; Jia et al., 2013). And studies have shown that CLCP policy can significantly reduce regional carbon emissions per capita, which suggests that there are obvious environmental benefits (Dai and Cao, 2015). However, in fact, merely evaluating environmental benefits of CLCP policy does not provide an overall basis for the decision of the Chinese government to further promote the policy nationally, and ignoring the economic benefits of policies is one-sided, which may further mislead decision-makers to make irrational choices. Therefore, studying economic benefits of the CLCP policy, both for decision-makers and for researchers, is a very important task. Do environmental benefits come at the expense of sacrificing economic development? Can environmental regulation and economic growth achieve a "win-win" situation? If the CLCP policy can achieve economic benefits, what is the underlying mechanism? All of these questions are worth studying.

To answer the above questions, based on macro panel data of Chinese prefecture-level cities and the micro data of Chinese microindustrial enterprises from 2001 to 2013, this article analyzes the causal effects of environmental regulation on economic growth and explores its underlying mechanism from the perspective of microenterprise behavior. The results show that the CLCP policy, as an effective tool of environmental regulation, can significantly improve regional GDP and GDP per capita, but the effect has an obvious time-lag. In addition, the effects become stronger with time. From the microenterprises analysis, it is found that although CLCP policy implementation has increased various production costs, it has also promoted enterprises' output and income. This conclusion is completely consistent with that of macroanalysis, in other words, microenterprises analysis is the microfoundation of macroeconomic growth. The reason for improvement of enterprises output is that under the pressure of an increase in production costs, enterprises do not choose the negative ways of trans-regional transferring; instead, they adopt positive measures of strengthening management, improving efficiency and increasing investment in innovation activities. Therefore, they overcome the negative impact brought by environmental regulations and increase their income.

The structure of this article is arranged as follows. Section 2 reviews the relevant literature. Section 3 introduces the policy background and theoretical analysis. Section 4 introduces the model and data. Specific empirical results and robustness tests are provided in Section 5. Section 6 analyzes the underlying mechanism of the economic benefits of environmental regulation from the perspective of enterprise behavior. The last section is the conclusions of the article.

\section{Literature review}

Studying the relationship between environmental regulation and economic growth is always an important issue in environmental economics. It has been analyzed by many studies, most of which mainly explain economic growth from the perspective of microenterprises (Pickman, 1998; Brunnermeier and Cohen, 2003). However, studies on the relationship between the two have not come to a unified conclusion. At first, scholars believe that environmental regulations can significantly hinder economic growth by increasing production costs and reducing enter- 
prise profits (Gray, 1987; Gray and Shadbegian, 2003). Christainsen and Haveman (1981) find that the inhibitory effect of environmental regulations may explain $0.27 \%$ of the labor efficiency and $0.5 \%$ of the production level; there is also time heterogeneity. With the deepening of research in this field, studies represented by the "Porter Hypothesis" proposed by Porter and van der Linde (1995) further improve the internal mechanism between environmental regulation and economic growth. The hypothesis holds that environmental regulation may encourage enterprises to innovate, improve their productivity and reduce their costs, which will offset the additional costs of environmental regulation and thus further promote economic growth (Johnstone et al., 2010; Feng et al., 2017). Meanwhile, other scholars hold that innovation may not only completely offset the cost caused by environmental regulation but also improve competitiveness and increase enterprise profits (Hamamoto, 2006; Aghion et al., 2016). Moreover, the "Porter Hypothesis" is further improved and strengthened. Many subsequent studies focus on whether the "Porter Hypothesis" exists. Mazzanti and Zoboli (2009) find that environmental regulations can affect economic benefits by improving the productivity of enterprises through an analysis of environmental regulation efficiency and labor productivity. Taylor (2012) evaluates the American "Acid and Plan" policy, and the results show that the policy curbed the development of SO2 control technology after 1995. Similarly, Shi et al. (2018) analyze the effects of environmental regulations on innovation and find that the policy would be negative for enterprise innovation and that there is an obvious spillover effects. In addition, other scholars research the economic benefits of environmental regulation from the perspective of regional heterogeneity and believe that the effect should be different in different regions. Through the study of the panel data of prefecture-level cities from 2004 to 2009, Zhao (2014) investigates the correlation among environmental regulation, regulation competition and regional industrial economic growth. The results show that environmental regulation is negative for the rate of regional economic growth, and the effect of regulation competition on economic growth is heterogeneous in different regions; specifically, it is positive in the eastern region, negative in the central region, and there is no significant impact in the western region. In addition to the above static study, some scholars have explored the dynamic relationship between environmental regulation and economic growth. Xie et al. (2012) use the Simultaneous Equation Model to test the dynamic relationship between environmental regulation and economic growth from 1996 to 2010 and find that the relationship has obvious heterogeneity among different regions. For the entire country and underdeveloped area, there is no causal relationship, while there is a two-way causality link for developed areas.

In addition to the above studies, currently, there are three research trends on the relationship between environmental regulation and economic growth. First, increasingly more scholars have begun to shift from the whole to different types of environmental regulations and aim at exploring the impact of different types of environmental regulations on economic growth (Böcher, 2012). Yuan and Liu (2013) believe that existing studies only study the relationship between environmental regulation and economic growth while ignoring the different effects of different types of environmental regulations. Therefore, they subdivide environmental regulation into two types, namely, a cost type and investment type, and investigate the impact of the two types on economic growth from 2004 to 2010; they find that the cost type had no effect on economic growth, while the investment type can significantly promote economic growth. Second, scholars have modified the traditional theory's bias that was limited only to the quantity 
of economic growth and have begun to analyze the impact of environmental regulations on the quality of economic growth. Based on the provincial panel data from 2001 to 2013, Huang and Gao (2016) use the Simultaneous Equations Model to investigate the impact of environmental regulations on economic growth quantity and quality, and they find that environmental regulations have a significant inhibiting effect on the quantity of economic growth, while they have a promoting effect on the quality of economic growth. Finally, one of the tasks of social science is to explain the causality of social phenomena, especially in economics. In view of this, a few scholars have begun to use the policy evaluation method of the "quasi-natural experiment" to analyze the causal relationship between environmental regulation and economic growth. Based on quasi-natural experiments of China's "two control zones" environmental policy, Hering and Poncet (2014) and Jefferson et al. (2013) analyze the impact of the policy on Chinese enterprise profits, costs and foreign direct investment (FDI) and believe that strict environmental regulation would increase enterprise profits and reduce foreign capital inflows; the causal effect is greater in countries with lower levels of environmental regulation.

It can be seen from the literature that the existing research focuses more on the effect and experience of environment governance of developed countries, especially on EU ETS (Jiang and Novák, 2004; Gagelmann and Frondel, 2005; Grubb et al., 2005; Hoffmann, 2007) . However, due to the large differences between developed countries and developing countries in terms of economic development degree and social systems, the analysis of environmental regulations in developed countries cannot provide a practical reference for developing countries, which is one of the existing research defects and deficiencies. Second, in terms of the CLCP policy, the current research is only limited to the analysis of its environmental benefits but ignores its economic benefits. Such a one-sided policy evaluation is not conducive to the government's comprehensive understanding of the overall effect of policy, which is bound to affect the promotion of policy nationwide, and ultimately affect the process of China's emissions reduction. Moreover, most of the studies are based on the perspectives of microenterprises performance, productivity and innovation (Stavins, 2008; Tomás et al., 2010; Anderson and Di Maria, 2011). These studies ignore the impact of the spillover effect of the changes in enterprise behaviors on regional economic growth, which is undesirable. In addition, due to the different research methods and objectives, each study adopts different indicators to measure environmental regulation (Ederington and Minier, 2003), and the conclusions obtained are quite different. Furthermore, the existing research is only a discussion and analysis of correlation, and the existence of endogenous problems makes the causal relationship between environmental regulation and economic growth to not be fully demonstrated.

Considering the defects in the existing research literature, this article attempts to compensate for the above deficiencies. The potential marginal contribution is as follows. First, considering the current research that focuses too much on the environmental regulations in developed countries, this study, based on the CLCP policy implementation in China, which is the world's most typical developing country, analyzes the economic benefits of the policy and its impact on microenterprise behavior to provide useful experience for the environmental governance of other developing countries. Second, in view of the one-sidedness of CLCP policy evaluation, this article analyzes the impact of CLCP policy on macroeconomic growth and microenterprise behavior from the perspective of economic benefits. Based on the existing research on environmental benefits, this article discusses economic benefits of CLCP policy to 
fully grasp the effects of the policy and to lay a decision-making foundation for the Chinese government to popularize CLCP policy nationwide. Third, to evaluate the economic benefits more comprehensively, this article, based on both macro data and micro data, explores a reliable microbasis for the conclusions of the macroanalysis and accurately evaluates the macro-effects of enterprise behaviors. This article abandons the isolation between macro and micro analysis in the previous literature and therefore deepens the understanding of the environmental regulation for decision makers. Finally, how to better deal with the endogeneity between environmental regulation and economic growth is the crux of the existing research. It requires an accurate extrapolation of the causal relationship between environmental regulation and economic growth for China, as the world's largest carbon emitter, concerning how to fulfill its commitments to global emissions reduction and developing its economy simultaneously. CLCP policy in eight cities and five provinces provides a perfect opportunity to analyze this problem. Therefore, this article attempts to take CLCP policy implementation as a "quasi-natural experiment" and use the difference-in-differences (DID) method to make a clear determination on the causal relationship between environmental regulation and economic growth to make up for the lack of existing research and to provide an empirical basis for the government to further regulate the environment.

\section{$3 \quad$ Policy background and theoretical analysis}

\subsection{Policy background}

For 40 years, China's economy has attained remarkable achievements. Although the rapid economic growth has improved the national income, it has also made the environmental quality deteriorate day by day. Environmental problems have become the focus of social attention. The extensive, energy-intensive mode of economic development made China the world's largest emitter of carbon dioxide in 2006, and its emissions continue to grow at a rate of approximately $6 \%$. Therefore, large amounts of greenhouse gas emissions directly result in global warming and determine the survival and development of human beings. Therefore, actively addressing climate change is not only a major challenge faced by all countries in the world but also a major mode for China to achieve green development. In addition, China is currently in the critical period of building a well-off society, industrialization and urbanization. At this stage, energy demand will continue to grow. How to effectively control greenhouse gas emissions and properly manage climate change while developing the economy and improving people's livelihood is a new issue. Therefore, the State Council of China has proposed a target for controlling greenhouse gas emissions by 2020 and has selected five provinces (Guangdong, Liaoning, Hubei, Shaanxi, and Yunnan) and eight cities (Tianjin, Chongqing, Shenzhen, Xiamen, Hangzhou, Nanchang, Guiyang and Baoding) to carry out low-carbon pilot (LCP) projects.

These pilot areas are required to compile a low-carbon development plan which requires them to fully incorporate climate change work into the "12th Five-Year" plan. These measures are shown in Table 1. It can be seen that local governments are required to prepare low-carbon devel- 
Economics: The Open-Access, Open-Assessment E-Journal 13 (2019-47)

Table 1: Specific Measures of Local Government in Pilot Areas

\begin{tabular}{ll}
\hline \multicolumn{1}{c}{ Main tasks } & \multicolumn{1}{c}{ Specific contents } \\
\hline $\begin{array}{l}\text { Carry out investigations and studies, clarify the pilot ideas, play a comprehensive guiding } \\
\text { role in planning, combine the work of adjusting industrial structure, optimizing energy } \\
\text { development plans }\end{array}$ & $\begin{array}{l}\text { structure, energy efficiency and increasing carbon sinks, and clearly propose the action } \\
\text { targets, key tasks and specific measures for controlling greenhouse gas emissions in the } \\
\text { region, reduce the intensity of carbon emissions, and actively explore the low-carbon and } \\
\text { green development model. }\end{array}$ \\
\hline $\begin{array}{l}\text { Formulate supporting } \\
\text { policies to support } \\
\text { low-carbon and green } \\
\text { development }\end{array}$ & $\begin{array}{l}\text { Play a synergistic effect in climate change, energy conservation and environmental } \\
\text { protection, new energy development, and ecological construction, actively explore } \\
\text { institutional mechanisms conducive to energy conservation and emission reduction and low- } \\
\text { carbon industry development, implement a responsibility system for controlling greenhouse } \\
\text { gas emissions, and explore effective government guidance and Economic incentives, } \\
\text { research and use of market mechanisms to promote the implementation of the goal of } \\
\text { controlling greenhouse gas emissions. }\end{array}$ \\
\hline
\end{tabular}

Combine local industry characteristics and development strategies, accelerate low-carbon technology innovation, promote low-carbon technology research and development, demonstration and industrialization, actively use low-carbon technology to transform and Establish industrial upgrade traditional industries, accelerate the development of low-carbon buildings, lowsystems characterized by carbon transportation, cultivate strategic emerging industries such as energy conservation, low-carbon emissions environmental protection and new energy. At the same time, we must closely follow the latest progress in technological progress in the low-carbon field, and actively promote the introduction of technology, digestion and absorption, and innovation or joint research and development with foreign countries.

Greenhouse gas emission data statistics and management systems
Strengthen the statistics of greenhouse gas emissions, establish a complete data collection and accounting system, strengthen capacity building, and provide institutional and personnel support.

Organize training activities for leading cadres at all levels and departments to improve the emphasis and understanding of climate change issues in decision making and

Advocate low-carbon green lifestyles and consumption patterns implementation. Vigorously carry out educational popularization activities, encourage lowcarbon lifestyles and behaviors, promote the use of low-carbon products, promote the concept of low-carbon life, and promote broad participation of all.

opment plans, establish industrial systems characterized by low-carbon emissions, establish greenhouse gas emission data statistics and management systems, formulate supporting policies of low-carbon and green development, and actively advocate low-carbon green lifestyles and consumption patterns to achieve carbon emissions reduction from all aspects. The above requirements and specific implementation contents are also the behaviors prescribed by local governments in reducing carbon emissions. 
Although local government has been supervised by central government, has the local government really implemented a series of strict measures? It is not sufficient to interpret local government's behavior only from the perspective of government documents and policy formulation. In view of this, we measure carbon emissions at provincial level to illustrate changes in carbon emissions in pilot areas, thus directly demonstrating effectiveness of CLCP policy, and indirectly indicating degree to which local governments have implemented various measures. It should be noted that carbon emission calculation here is calculated according to the standard calculation formula, that is, carbon emission $=$ coal consumption $\times 0.7329+$ oil consumption $\times 0.5574+$ natural gas energy consumption $\times 0.4226$, where the emission factors of various energy sources are the average of the carbon emission factors published by the DOE, the Japan Energy Economic Research Institute, the China National Science and Technology Commission Climate Change Project, and the National Development and Reform Commission Energy Research Institute. In order to better compare the carbon emissions between pilot areas and non-pilot areas, we compare total carbon emissions and carbon emissions per capital in each region. The specific results are shown in Figure 1. It can be seen that compared with non-pilot areas, carbon emissions of pilot areas after CLCP policy implementation have been significantly reduced. Although there is a time lag in the reduction, it is undeniable that CLCP policy implementation has effectively reduced carbon emissions in the pilot areas and achieved expected environmental benefits. Therefore, from this perspective, local government has followed the policies formulated by central government, actively implemented measures, and achieved regional carbon emissions reduction. It can be seen from the above discussion that the government is attempting to explore a low-carbon development path through the CLCP policy to transform the

Figure 1: Trend changes of carbon emission in pilot and non-pilot areas
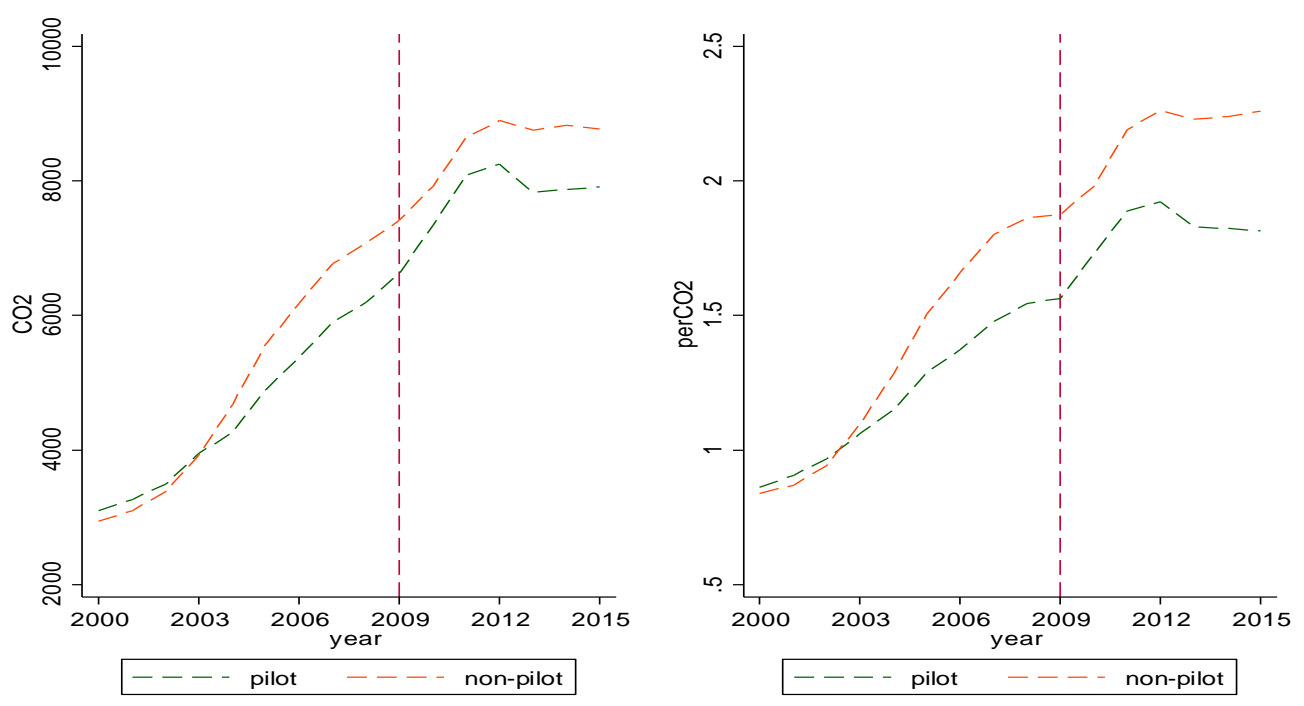
traditional extensive mode and to improve environmental quality. Although the environmental effects of the CLCP policy have been proved by a large number of literature, its economic benefits have been ignored by scholars. Therefore, an analysis of the economic benefits of the CLCP policy is the main task of this article.

\subsection{Theoretical analysis}

Although the CLCP policy is an important tool of environmental regulation by the Chinese government to reduce carbon emissions and improve environmental quality, the relationship between environmental regulation and economic growth is not clear. Through the internal mechanism, environmental regulation has an impact on economic growth mainly in the following ways.

First, from the macroeconomic structure of the entire region, environmental regulation can change the existing industrial structure and layout. Environmental regulations raise the standards of pollution emissions, which will encourage pilot areas to gradually eliminate the enterprises that fail to meet the standards and provide opportunities for other enterprises in the clean industry. Furthermore, environmental regulations can create a good external environment for higher-end industries to improve environmental quality and build green development. This substitution effect can promote the adjustment and optimization of the regional industrial structure and therefore inject new impetus into regional economic growth. Second, environmental regulations implementation directly affects the decision-making of enterprises. Cost increase affects the entry and exit of enterprises, changes the original market structure, and intensifies the level of market competition. Such market competition promotes enterprises to strengthen management, improve efficiency and input more resources for innovation to gain greater competitiveness and avoid being eliminated. When all the enterprises in the entire industry adopt a positive strategy, there is no doubt that the productivity and technological innovation of the whole industry can be improved, and the spillover effect of technological innovation will greatly affect the technological progress of upstream and downstream related industries, thus improving the technological level of the entire economic system and ultimately increasing the economic output at the regional level. Third, for the trade that drives economic growth, environmental regulations are conducive to the export competitiveness of the clean industry and do not lead to the loss of the export advantage of the pollution-intensive industry, and thus driving the growth of regional export trade in the long run and promoting the economy. In addition, environmental regulation can improve accumulation of regional human capital, effectively promote enterprises to carry out environmental technology innovation and reduce the cost of environmental regulation, so as to promote economic growth.

To sum up, environmental regulation accordingly promotes economic growth by industrial restructuring, market structure optimization, the spillover effect of technological innovation, the improvement of productivity and regional human capital accumulation. Therefore, this article considers that environmental regulation does not impede regional economic growth, but that on the contrary, it can significantly promote regional economic growth and achieve a "win-win" situation. However, because it takes some time to change factors such as enterprise decisionmaking, strategy adjustment and innovation input, the implementation of the CLCP policy can- 
not exert its positive promotion effect immediately but has a time-lag effect. In other words, the economic benefits generated by environmental regulation are not effective in the current period, but the result of long-term and stable policy implementation. The specific hypothesis is as follows:

Hypothesis 1(H1): The CLCP policy implementation promotes local economic growth at the macrolevel, and the promotion effect can be gradually strengthened with time.

Although the CLCP policy can promote economic growth at the macro-regional level, its most direct impact is on micro enterprises, whose original living environment could be changed. As the CLCP policy sets out new requirements on the carbon emissions of enterprises, enterprises need to adjust existing products, production processes and pollution emissions to meet them. However, no matter which path the enterprise chooses, undoubtedly, the production costs will increase, which will force the enterprise to make new choices. When enterprises are faced with changes in external environment constraints, they are either forced to stop and exit from the market by local governments for failing to reduce environmental pollution in the production process or carry out technological innovation through R\&D investment. As the preferred development strategy of enterprises, innovation in clean technology alleviates the pressure of environmental regulation on enterprises and overcomes the negative impact of the external cost increase to realize the "Porter Hypothesis". In addition to technical innovation, enterprises also conduct management reform of the internal production process to attempt to improve the production efficiency by strengthening management to increase the output per unit input and to offset the cost increase of environmental regulation, and thus promoting economic growth. Of course, enterprises can also choose to transfer across regions or exit from the market to completely avoid the impact of environmental regulation on enterprises. However, the existence of transfer costs forces the enterprise not to exit from the market but to compensate for cost increase and to improve enterprise income by strengthening the internal management, improving operating efficiency and carrying out innovation. Therefore, based on the above analysis, we propose the second hypothesis, which is as follows:

Hypothesis 2(H2): the CLCP policy implementation encourages enterprises to compensate for production costs increase by strengthening the internal management, improving efficiency and increasing innovation, so as to improve enterprises output and income.

In the following context, we conduct an empirical analysis of these hypotheses.

\section{$4 \quad$ Model and data}

\subsection{Model}

In order to test the economic benefits of environmental policy, this paper takes CLCP policy implementation as a quasi-natural experiment, and uses DID method for causal identification to investigate whether CLCP policy promote regional economic growth. The DID method mainly identifies the "net effect" of policy intervention by comparing the difference in economic 
growth between pilot and non-pilot areas. Therefore, we select the variable Pilot $_{i}$ to represent whether this city is the pilot area or not. If it is a pilot area, the value is 1 . It represents the policy treatment group, which is the five provinces and eight cities where CLCP policy is implemented; otherwise, the value is 0 . It represents the policy control group.

The variable Time $e_{t}$ indicates whether the time is after 2010 or not, and if it is after 2010, the value is 1 ; otherwise, it is 0 . Thus, this study constructs a two-way fixed effects model, thereby evaluating net effect of CLCP policy on regional economic growth. The specific model is shown below.

$$
G D P_{i t}=\alpha+\beta \text { Pilot }_{i} \times \text { Time }_{t}+\gamma \text { Control }_{i t}+\delta_{t}+\mu_{i}+\varepsilon_{i t}
$$

Where $i$ and $t$ represent the $i$ th pilot and the $t$ th year, respectively, GDP $i t$ is the dependent variable, that is, regional economic growth, which is measured by the GDP of the city and per capita GDP, $\delta_{t}$ is the time fixed effects, $\mu_{i}$ is the individual fixed effects in the province, $\varepsilon_{i t}$ is the error term, and Control $_{i t}$ is the selected series of control variables. For the above model, the estimator of coefficient $\beta$ is the focus of our concern. It measures the net effect of the CLCP policy on economic growth. If $\beta>0$, it shows that the CLCP policy promotes economic growth; otherwise, the policy hinders regional economic growth.

Equation (1) only evaluates the average effect of CLCP policy on urban economic growth. In fact, the implementation of the CLCP policy has a long-term promoting effect on the local economic development mode, technology research and development, etc. Therefore, environmental regulation is not necessarily effective in the current period and may have a longterm promoting effect on economic development. To test this expectation, Equation (2) is extended on the basis of Equation (1) to test the dynamic effect of the CLCP policy on economic growth. The specific equation is as follows:

$$
G D P_{i t}=\alpha+\sum_{k \in\{1,2,3,4\}} \beta_{k} \text { Pilot }_{i} \times \text { Time }_{k}+\gamma \text { Control }_{i t}+\delta_{t}+\mu_{i}+\varepsilon_{i t}
$$

In the above equation, the variable Pilot $_{i} \times$ Time $_{k}$ expresses the annual dummy variable (where $\mathrm{k}=1,2$ ) after the implementation of the CLCP policy in the pilot province. For example, this policy was issued in 2010; thus, $\mathrm{k}=1$ in 2011, the variable Pilot $_{i} \times$ Time $_{k}=1$ and is 0 for the rest of the year. $\beta_{k}$ measures the impact of this policy on economic growth after the policy implementation for the $\mathrm{k}$ th year. The explanation of the other variables in Equation (2) is the same explanation as in Equation (1).

The above model is used to evaluate the effect of environmental regulation on economic growth by the DID method. However, there is an important premise in the application of the DID method, namely, the parallel trend hypothesis. That is, in the absence of a CLCP policy, the difference in economic growth between the treatment group and the control group does not change significantly over time. If the factors before the implementation of environmental regulation make the economic growth level between the treatment group and the control group change significantly, then the parallel trend hypothesis will not be satisfied, which will lead to a bias of the regression results. Therefore, to more accurately evaluate the real effect of environmental regulation on economic growth, the parallel trend hypothesis needs to be tested in this 
article. This article uses methods commonly used in a large number of the literature, and the specific model is as follows:

$$
G D P_{i t}=\alpha+\beta \text { Pilot }_{i} \times \text { Time }_{t}+\sum_{j \in\{-7,-6, \cdots,-2,-1\}} \beta_{j} \text { Treat }_{j}+\gamma \text { Control }_{i t}+\delta_{t}+\mu_{i}+\varepsilon_{i t}
$$

In Equation (3), Treat $_{j}$ is a dummy variable, which represents the interaction between the dummy variables of the different years before CLCP policy implementation and the dummy variables of the pilot to evaluate the policy effect of different years before CLCP policy implementation. If the coefficients $\beta_{-7}, \beta_{-6}, \ldots, \beta_{-2}$ and $\beta_{-1}$ are not significant, then there is no systematic difference between the treatment group and control group before the CLCP policy implementation. Otherwise, there is a systematic difference, namely, the evaluation of DID is biased.

\subsection{Data}

\subsubsection{Data source}

To more comprehensively test the above assumptions, this article selects the panel data of China prefecture-level cities and China's Industrial Enterprise Database from 2001 to 2013. The reasons for the end date of 2013 are as follows. First, China started the carbon emission trading pilot program in five cities (Beijing, Tianjin, Shanghai, Chongqing, and Shenzhen) and two provinces (Guangdong and Hubei) in 2013. This pilot covers some of the same areas where the CLCP policy is implemented. If the investigation period is extended beyond 2013 at this time, the two policies will interact with one another, and it is difficult to separate the net effects of the CLCP policy. Second, China's economy entered a new normal after 2013. Both the domestic economic situation and the international economic environment underwent major changes. Many external factors are difficult to quantify and are included in the model for control, which inevitably affects the policy effect to be evaluated. Therefore, to avoid the interference of more factors and the pollution of the samples in the control group, the time of investigation was selected from 2001 to 2013 to evaluate the economic effects of the CLCP policy more accurately. This article uses China's 286 prefecture-level cities as subjects, and the macrodata come from the "China City Statistical Yearbook". As FDI is expressed in dollars, the annual exchange rate conversion adjustment is used. The relevant contents of the implementation time, city and specific measures of the CLCP policy come from the "notice of the office of national development and reform commission on the pilot work of carbon emission trading". The microdata come from China's Industrial Enterprise Database. The processing of the microdata is as follows. First, the abnormal samples with missing codes, missing indicators and the incorrect year of enterprise establishment are eliminated. Second, generally accepted accounting standards are used in this article to eliminate the sample with total assets, total fixed assets, net fixed assets, total current assets and an employment number less than 0 . 


\subsubsection{Variables}

This article aims to analyze the effect of environmental regulations on regional economic growth. Therefore, based on the relevant literature, this article selects regional GDP and per capita GDP to measure economic growth and conducts a price adjustment and logarithm to maintain the comparability of the research conclusions. This article takes whether the city is pilot city or not as the explanatory variable. If the city has implemented the CLCP policy, the value is 1 ; otherwise, it is 0 .

In addition, several other factors are selected as control variables. Control variables selection mainly considers the following factors. Investment level is a key factor that influences regional economic growth, and investment driving is an important transmission path for economic growth (Anderson, 1990). Therefore, this article selects the logarithm of social fixed asset investment to measure it. China's demographic dividend produced by labor force input plays an important role in economic growth, and is an important resource endowment that affects the economic development of a region (Hondroyiannis and Papapetrou, 2001; Mello, 2008); accordingly, this article chooses the logarithm of total employment to measure the labor input in this area. On the macrolevel, government fiscal expenditure scale can influence economic growth through public services and public fiscal expenditure channels (Landau, 1986), and the proportion of government budget expenditures to GDP is chosen to measure it. At the same time, the level of industrialization is an important indicator for determining the economic development path of a country (Moreno-Brid et al., 2005). This article chooses the ratio of the output value of the secondary industry to GDP to measure the level of industrialization. The higher this indicator, the higher the level of industrialization, and vice versa. The education level of the region is expressed by the ratio of the number of students in the general colleges and universities to the total population of the region, which reflects the level of human capital accumulation in the region. At the same time, considering the impact of the savings rate on economic growth through social investment and consumption (Hamberg, 1969), we choose the ratio of the total savings of urban and rural residents to GDP to measure it because China's rapid economic growth shows a sustained high savings rate. In addition, FDI promotes regional growth by reducing inefficient domestic production and accelerating technological progress (Alfaro et al., 2002; Berthélemy and Démurger, 2000). Therefore, through the calculation of "total foreign direct investment/regional GDP", this article measures regional openness.

To further interpret the results of the macroanalysis, this article also analyzes the changes in enterprise behavior caused by the CLCP policy based on the microenterprise data. Therefore, this article selects different indicators to measure the costs and benefits of the enterprises to illustrate the impact of environmental regulations on enterprise output and income. In addition, this article also compares the results of the microanalysis with the results of the macroanalysis to explain the differences in the impact of environmental regulation on the macroeconomy and income of microenterprises. Furthermore, to deeply investigate the impact of environmental regulations on enterprise behavior, this article investigates the effect of the CLCP policy on various behaviors of enterprises, such as analyzing enterprises' cross-regional transfer, strengthening internal management, improving productivity and increasing innovation. In addition, existing 
Economics: The Open-Access, Open-Assessment E-Journal 13 (2019-47)

Table 2: A description of specific variables and the descriptive statistics

\begin{tabular}{|c|c|c|c|c|c|}
\hline Variable & Description & Calculation method & Mean & Min & Max \\
\hline \multicolumn{6}{|c|}{ A: Macroregional-level variables } \\
\hline gdp & Regional GDP & Regional GDP (in log) & 15.06 & 10.74 & 18.754 \\
\hline pergdp & Regional per capita GDP & Regional per capita GDP (in log) & 9.217 & 5.106 & 12.393 \\
\hline firmnumber0 & \multirow{2}{*}{$\begin{array}{l}\text { Number of new } \\
\text { enterprises }\end{array}$} & Number of new enterprises under the age of one year & 4.397 & 0 & 273 \\
\hline firmnumber1 & & $\begin{array}{c}\text { Number of new enterprises under the age of two } \\
\text { years }\end{array}$ & 13.673 & 0 & 665 \\
\hline pilot & CLCP policy & Dummy variable $(0,1)$ & 0.248 & 0 & 1 \\
\hline investment & Fixed asset investment & Fixed asset investment (in log) & 14.849 & 11.147 & 18.522 \\
\hline labor & Labor input & Total regional employment (in log) & 3.392 & 1.399 & 6.828 \\
\hline government & Government size & (Government budget expenditure / GDP) ×100 & 13.23 & 0.275 & 234.876 \\
\hline open & Regional openness & (Total foreign direct investment / GDP) $\times 100$ & 2.335 & 0.003 & 47.627 \\
\hline industry & $\begin{array}{l}\text { Level of } \\
\text { industrialization }\end{array}$ & (Output value of the secondary industry / GDP) $\times 100$ & 48.36 & 9 & 90.97 \\
\hline education & Human capital & $\begin{array}{l}\text { (Number of students in the general colleges and } \\
\text { universities/Total population of the region) } \times 100\end{array}$ & $56,062.4$ & 17.246 & 92.666 \\
\hline save & Total savings rate & Total savings of urban and rural residents/GDP & 0.651 & 0.009 & 7.751 \\
\hline \multicolumn{6}{|c|}{ B: Microenterprise-level variables } \\
\hline income & \multirow{3}{*}{ Enterprise income } & Main business income (in log) & 10.778 & 8.195 & 14.796 \\
\hline revenue & & Enterprise operating profit (in log) & 7.740 & 0 & 12.375 \\
\hline profit & & Total enterprise profits (in log) & 7.610 & 0 & 12.285 \\
\hline salestax & \multirow{5}{*}{ Enterprise cost } & Product sales tax and surcharge & 3.991 & 0 & 8.912 \\
\hline salesfee & & Product sales expenses & 7.101 & 0 & 11.680 \\
\hline $\operatorname{tax}$ & & Enterprise payable VAT & 6.868 & 0 & 11.160 \\
\hline paytax & & Enterprise payable income tax & 5.834 & -1.238 & 10.193 \\
\hline wage & & Enterprise payable total wages & 8.086 & 4.868 & 11.674 \\
\hline managemcosts & Enterprise management & Enterprise management costs & 7.593 & 3.258 & 11.384 \\
\hline laborprofitratio & \multirow{2}{*}{ Enterprise efficiency } & Operating profit/Number of employees & 33.976 & -3198 & 29588 \\
\hline capitalprofitratio & & Operating profit/Total assets & 0.100 & -18.969 & 175.470 \\
\hline newproduct & \multirow{3}{*}{ Enterprise innovation } & Output value of new products (in log) & 9.490 & 0 & 12.251 \\
\hline newproductrate & & New product output/Main business income & 0.035 & 0 & 57.772 \\
\hline exportsize & & Total export volume of enterprises (in log) & 9.845 & 0 & 13.691 \\
\hline size & Enterprise size & Total assets (in log) & 10.493 & 7.207 & 14.497 \\
\hline age & Enterprise age & Enterprise age (in log) & 2.168 & 0.693 & 3.332 \\
\hline labor & Labor input & Number of employees (in log) & 5.152 & 2.079 & 8.074 \\
\hline debt & Enterprise debt & Total enterprise debt (in log) & 9.665 & 3.970 & 14.047 \\
\hline right & Owner's equity & Enterprise owner's equity (in log) & 9.714 & 0 & 13.682 \\
\hline subsidy & Government subsidy & $\begin{array}{l}\text { If the enterprise is subsidized, the value is } 1 \text {; } \\
\text { otherwise, } 0\end{array}$ & 0.385 & 0 & 1 \\
\hline
\end{tabular}


studies show that factors such as enterprise size, the asset-liability ratio, age and owner's equity have important effects on enterprise income and decision-making. Therefore, this article selects the logarithm of total assets to measure enterprise size. The level of enterprise debt is measured by the logarithm of total enterprise debt, and the level of labor input in the production process is illustrated by the logarithm of the number of employees. At the same time, considering the influence of subsidy income on decision-making, the dummy variable of whether enterprises receive a government subsidy or not is used to represent government subsidy. A description of the specific variables and statistics are shown in Table 2.

\section{$5 \quad$ Empirical test}

\subsection{The impact of the CLCP policy on regional economic growth}

In this article, model (1) is regressed based on the two-way fixed effects to investigate the effect of the CLCP policy on economic growth. The specific results are shown in Columns (1)-(4) in Table 3. It can be seen from the table that regardless of whether regional economic growth is measured by regional GDP or per capita GDP, the implementation of the CLCP policy has a promoting effect on the economic growth of pilot cities, and the effect is significant at the $1 \%$ confidence level. This result shows that environmental regulation can promote regional economic growth while improving urban environmental quality to thus achieve a "win-win" situation between environmental governance and economic development. In addition,the fixed asset investment plays a significant role in promoting the local economy, which also provides empirical evidence for China's growth mode that relies on investment in the past decades. At the same time, the industrialization level measured by the ratio of the output value of the secondary industry to the regional GDP has a significant promoting effect on economic growth, which indicates that industrialization makes an important contribution to China's economic transformation.

\subsection{The dynamic effect test of the CLCP policy on regional economic growth}

Columns (1)-(4) in Table 3 show that environmental regulation has a significant promoting effect on economic growth, but it suggests only the average effect of the CLCP policy on economic growth. In fact, the implementation of the CLCP policy has a certain continuity. Environmental regulation will have a long-term effect on economic growth by transforming the local economic development mode, changing resource allocation and carrying out technological innovation. Moreover, the effect of the policy on economic growth is not necessarily effective currently. Therefore, it can be concluded that the implementation of the CLCP policy has a certain long-term impact on regional economic growth. To prove the theoretical expectation, we perform a regression analysis in model (2), and the specific results are shown in Columns (5)(8) in Table 3. It can be seen from the dynamic effect test that the CLCP policy has a long-term promoting effect on economic growth, and Column (7) in Table 3 indicates that the promoting effect is not effective in the current period, but there is a significant time lag in its effect. At the 
same time, it can be seen from the evaluation coefficient that with the implementation time of the CLCP policy, the promotion effect of the policy on regional economic growth is gradually strengthened. The dynamic effect test shows that the CLCP policy has a significant long-term promoting effect on economic growth, and this effect gradually increases over time.

Table 3: The impact of the CLCP policy on regional economic growth

\begin{tabular}{|c|c|c|c|c|c|c|c|c|}
\hline & \multicolumn{2}{|c|}{ gdp } & \multicolumn{2}{|c|}{ pergdp } & \multicolumn{2}{|c|}{ gdp } & \multicolumn{2}{|c|}{ pergdp } \\
\hline & $(1)$ & $(2)$ & (3) & (4) & (5) & (6) & $(7)$ & $(8)$ \\
\hline Pilot $\times$ Time & $\begin{array}{c}0.026^{* * *} \\
(0.006)\end{array}$ & $\begin{array}{c}0.019 * * * \\
(0.005)\end{array}$ & $\begin{array}{c}0.032 * * * \\
(0.007)\end{array}$ & $\begin{array}{c}0.034^{* * *} \\
(0.007)\end{array}$ & & & & \\
\hline${\text { Pilot } \times \text { Time }_{1}}_{1}$ & & & & & $\begin{array}{l}0.017^{*} \\
(0.010)\end{array}$ & $\begin{array}{l}0.018^{* *} \\
(0.008)\end{array}$ & $\begin{array}{c}0.020 \\
(0.013)\end{array}$ & $\begin{array}{l}0.025^{* *} \\
(0.012)\end{array}$ \\
\hline Pilot $\times$ Time $_{2}$ & & & & & $\begin{array}{l}0.022 * * \\
(0.010)\end{array}$ & $\begin{array}{l}0.019 * * \\
(0.008)\end{array}$ & $\begin{array}{c}0.030^{* *} \\
(0.013)\end{array}$ & $\begin{array}{c}0.034^{* * *} \\
(0.012)\end{array}$ \\
\hline Pilot $\times$ Time $_{3}$ & & & & & $\begin{array}{l}0.021^{* *} \\
(0.010)\end{array}$ & $\begin{array}{l}0.015^{*} \\
(0.008)\end{array}$ & $\begin{array}{l}0.030 * * \\
(0.013)\end{array}$ & $\begin{array}{c}0.033^{* * *} \\
(0.012)\end{array}$ \\
\hline 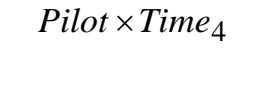 & & & & & $\begin{array}{c}0.043 * * * \\
(0.010)\end{array}$ & $\begin{array}{c}0.023 * * * \\
(0.008)\end{array}$ & $\begin{array}{c}0.049 * * * \\
(0.013)\end{array}$ & $\begin{array}{c}0.044 * * * \\
(0.012)\end{array}$ \\
\hline Control variables & NO & YES & NO & YES & NO & YES & NO & YES \\
\hline $\begin{array}{l}\text { Individual fixed } \\
\text { effects }\end{array}$ & YES & YES & YES & YES & YES & YES & YES & YES \\
\hline Time fixed effects & YES & YES & YES & YES & YES & YES & YES & YES \\
\hline _cons & $\begin{array}{c}14.317^{* * *} \\
(0.004)\end{array}$ & $\begin{array}{c}13.160^{* * *} \\
(0.068)\end{array}$ & $\begin{array}{c}8.526 * * * \\
(0.006)\end{array}$ & $\begin{array}{c}7.568^{* * *} \\
(0.096)\end{array}$ & $\begin{array}{c}14.317^{* * *} \\
(0.004)\end{array}$ & $\begin{array}{c}13.162 * * * \\
(0.068)\end{array}$ & $\begin{array}{c}8.526 * * * \\
(0.006)\end{array}$ & $\begin{array}{c}7.571^{* * *} \\
(0.096)\end{array}$ \\
\hline $\mathrm{N}$ & 3,354 & 3,218 & 3,343 & 3,218 & 3,354 & 3,218 & 3,343 & 3,218 \\
\hline $\mathrm{F}$ & $12,378.433$ & $11,636.537$ & $6,422.702$ & $5,020.031$ & $10,062.851$ & $10,110.290$ & $5,218.625$ & 4,363.066 \\
\hline r2 & 0.981 & 0.988 & 0.965 & 0.972 & 0.981 & 0.988 & 0.965 & 0.972 \\
\hline
\end{tabular}

Note: (1) The values in brackets are standard errors; $(2) *, * *$, and *** indicate significance at the confidence levels of $10 \%$, $5 \%$, and $1 \%$, respectively.

\subsection{Robustness tests}

To further guarantee the reliability of the results, this article uses the parallel trend assumption required by the DID method, adopts a counter factual test, removes heterogeneous samples, removes policy interference and introduces covariates to test the robustness of the results as follows. 


\subsubsection{Parallel trend hypotheses test}

There is an important precondition, namely, the parallel trend hypotheses, when using the DID method to evaluate the impact of the CLCP policy on local economic growth. First, we visually demonstrate the changes in GDP between the treatment group and the control group through data to test parallel trend hypotheses. Therefore, we respectively draws temporal variation graphs of GDP and GDP per capital, and details are shown in Figure 2. It can be seen that before LCP policy implementation there is no significant difference between the treatment group and the control group, and they maintain long-term parallel growth. After policy implementation, on the contrary, there is a big difference in economic growth between the two. Treatment group's economic growth is gradually higher than that of control group, the change of GDP per capital also shows the same trend, and growth rate of GDP per capital is even more obvious(the slope of the curve). The results in the Figure 2 preliminary indicate that LCP policy is conducive to economic growth in pilot areas, laying foundation for subsequent empirical analysis.

Second, if the CLCP policy has no external impact, the development trend between the treatment group and the control group should be parallel, and there should be no systematic differences over time. Therefore, this article conducts a regression analysis in model (3). Specifically, we assume that the time for policy intervention of CLCP policy is advanced, and this is included in the model. If the policy effect of the hypothetical year is significant, then it indicates that there are other random factors between the treatment group and the control group, that is, it does not meet the parallel trend. The contrary situation proves that the parallel trend is satisfied, and the specific results are shown in Table 4. In Table 4, Treat ${ }_{i}$ represents the year effect before the policy implementation. From the results it can be seen that the advance of the year of policy intervention did not bring a significant effect. At the same time, the policy effect is still significant, and the effect of the control variables do not change significantly; thus, it is not

Figure 2: Trend changes of economic growth in pilot and non-pilot areas
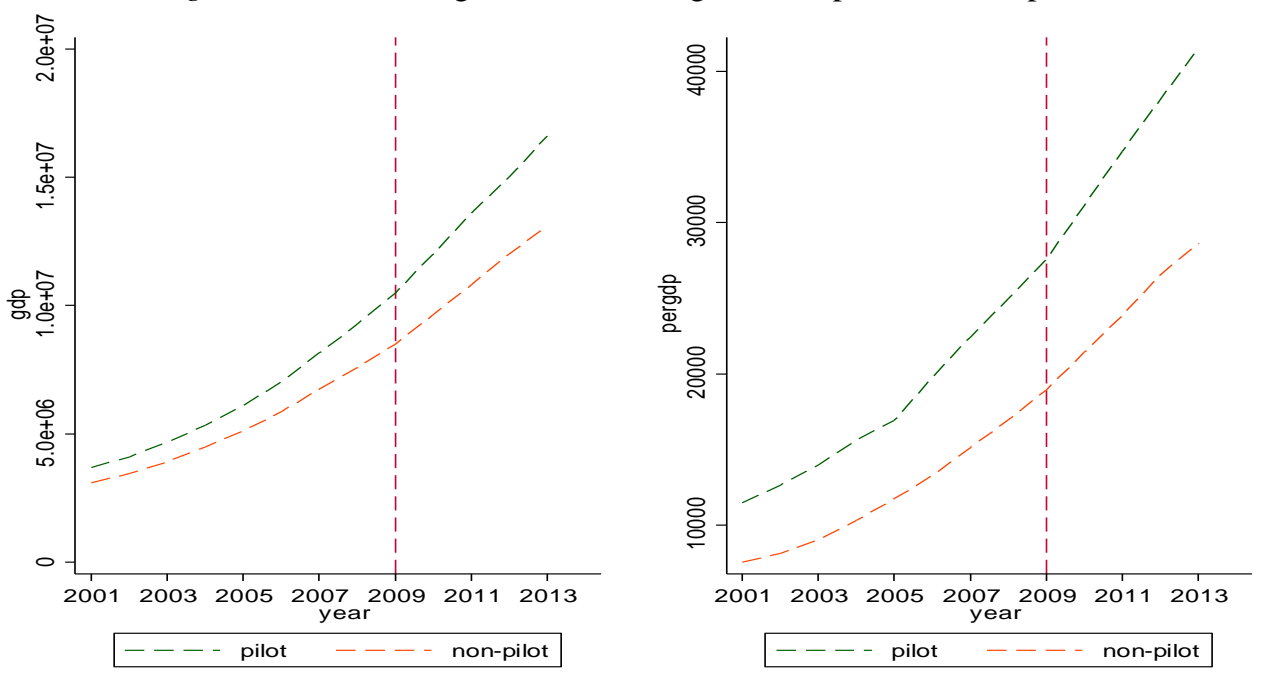
Table 4: Parallel trend hypotheses test

\begin{tabular}{|c|c|c|c|c|c|c|}
\hline & \multicolumn{3}{|c|}{ gdp } & \multicolumn{3}{|c|}{ pergdp } \\
\hline & (1) & (2) & (3) & (4) & (5) & (6) \\
\hline \multirow[t]{2}{*}{ Pilot $\times$ Time } & $0.017 * *$ & $0.013^{*}$ & $0.014^{*}$ & $0.022 * *$ & $0.028 * * *$ & $0.048 * * *$ \\
\hline & (0.008) & $(0.007)$ & $(0.008)$ & $(0.011)$ & $(0.010)$ & $(0.011)$ \\
\hline \multirow[t]{2}{*}{ Treat $_{-1}$} & -0.007 & -0.014 & -0.018 & -0.010 & -0.018 & $-0.031^{*}$ \\
\hline & $(0.012)$ & $(0.010)$ & $(0.012)$ & $(0.015)$ & $(0.014)$ & $(0.016)$ \\
\hline \multirow[t]{2}{*}{ Treat $_{-2}$} & -0.008 & -0.002 & -0.009 & -0.001 & 0.003 & -0.012 \\
\hline & $(0.012)$ & $(0.010)$ & $(0.011)$ & $(0.015)$ & $(0.014)$ & $(0.016)$ \\
\hline \multirow[t]{2}{*}{ Treat $_{-3}$} & -0.016 & -0.009 & -0.012 & -0.014 & -0.007 & -0.016 \\
\hline & $(0.012)$ & $(0.010)$ & $(0.011)$ & $(0.015)$ & $(0.014)$ & $(0.016)$ \\
\hline \multirow[t]{2}{*}{ Treat $_{-4}$} & -0.018 & -0.010 & -0.016 & $-0.039 * *$ & $-0.029 * *$ & $-0.038 * *$ \\
\hline & $(0.012)$ & $(0.010)$ & $(0.011)$ & $(0.015)$ & $(0.014)$ & $(0.016)$ \\
\hline \multirow[t]{2}{*}{ Treat $_{-5}$} & -0.016 & -0.008 & -0.008 & -0.015 & -0.006 & -0.004 \\
\hline & $(0.012)$ & $(0.010)$ & $(0.011)$ & $(0.015)$ & $(0.014)$ & $(0.016)$ \\
\hline \multirow[t]{2}{*}{ Treat_6 } & -0.011 & -0.006 & -0.002 & -0.010 & -0.002 & 0.007 \\
\hline & $(0.012)$ & $(0.010)$ & $(0.011)$ & $(0.015)$ & $(0.014)$ & $(0.016)$ \\
\hline \multirow[t]{2}{*}{ Treat_7 } & -0.003 & -0.001 & 0.002 & -0.002 & 0.004 & 0.017 \\
\hline & $(0.012)$ & $(0.010)$ & $(0.011)$ & $(0.015)$ & $(0.014)$ & $(0.016)$ \\
\hline Control variables & NO & YES & YES & NO & YES & YES \\
\hline Individual fixed effects & YES & YES & YES & YES & YES & YES \\
\hline Time fixed effects & YES & YES & YES & YES & YES & YES \\
\hline \multirow[t]{2}{*}{ _cons } & $14.317 * * *$ & $13.158 * * *$ & $12.917 * * *$ & $8.526 * * *$ & $7.566 * * *$ & $7.527 * * *$ \\
\hline & $(0.004)$ & $(0.069)$ & $(0.085)$ & $(0.006)$ & $(0.097)$ & $(0.117)$ \\
\hline $\mathrm{N}$ & 3,354 & 3,218 & 2,414 & 3,343 & 3,218 & 2,414 \\
\hline $\mathrm{F}$ & $8,038.846$ & $8,608.421$ & $5,668.951$ & $4,176.565$ & $3,719.185$ & $2,562.552$ \\
\hline r2 & 0.981 & 0.988 & 0.986 & 0.965 & 0.972 & 0.969 \\
\hline
\end{tabular}

Note: (1) The values in brackets are standard errors; $(2) *, * *$, and *** indicate significance at the confidence levels of $10 \%, 5 \%$, and $1 \%$, respectively.

reported here. Given that urban growth in eastern China is higher than in the central and is still significant, and the effect of the control variables do not change significantly; thus, it is not reported here. Given that urban growth in eastern China is higher than in the central and western regions, this geographical advantage may further affect the parallel trend. Therefore, the cities in the eastern region are excluded. The results that are shown in Columns (3) and (6) in Table 4 
suggest no significant differences. Therefore, the regression results in Table 4 indicate that the treatment group and the control group maintain a common development trend and that there is no systematic difference, which also indicates that the results of evaluating the effect of the CLCP policy on local economic growth with the DID method are credible.

In addition, to further test the parallel trend, this article estimates the policy effect of all years before and after the implementation of the CLCP policy. The specific results are shown in Figures 3 and 4. Figure 3 mainly shows the dynamic effect of the CLCP policy on gdp, and Figure 4 mainly shows the dynamic effect of the CLCP policy on pergdp. In the figures, the horizontal axis represents the year, and the vertical axis represents the impact of the CLCP policy on economic growth in this year. As seen from the figures, the effect of year before 2010 is not significant, which indicates that the parallel trend hypothesis is satisfied, while after 2010, the policy effect gradually increased, which indicates that the policy has a long-term promoting effect on economic growth. These results are completely consistent with the conclusions in Table 4.
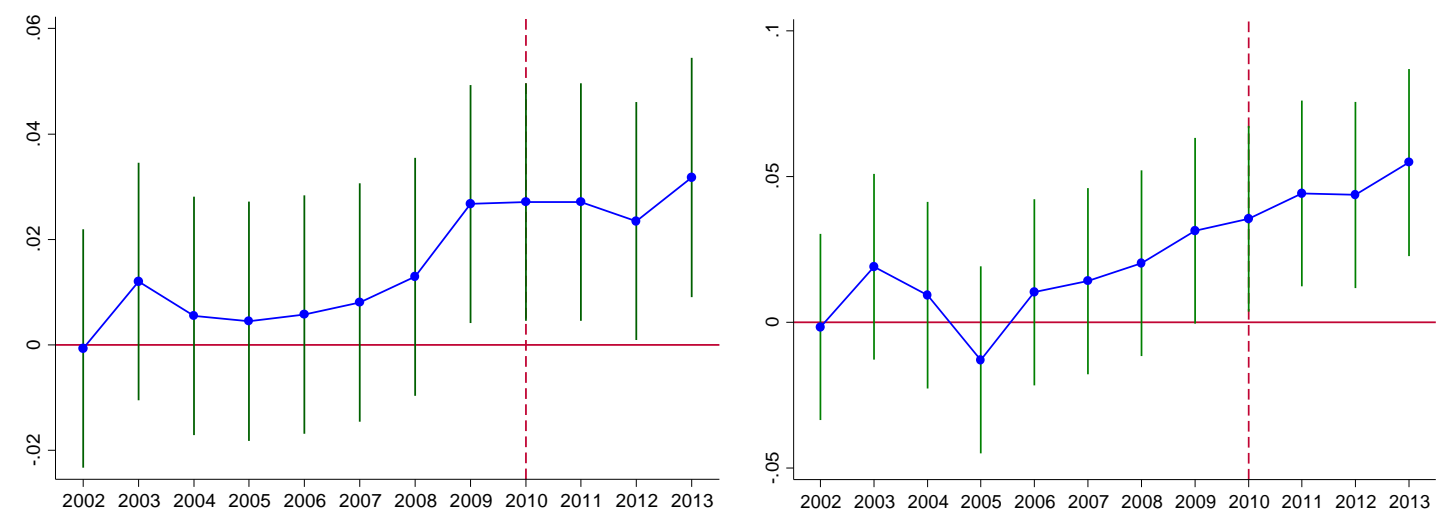

\subsubsection{PSM-DID method test}

From the parallel trend test in Table 4, we know that there is no significant difference in economic growth between the treatment group and the control group before the implementation of the CLCP policy. However, to further reduce the evaluation bias and potential endogeneity caused by DID, the robustness test of PSM-DID is also adopted in this study. The specific matching process is as follows. First, a probit regression was performed on all control variables to the variable pilot, and the trend score was calculated. The regression results show that investment, government, industry, education and savings rate have a significant influence on the explained variable pilot. Second, the nearest neighbor match was used to evaluate the differences between the treatment group and the control group in the impact of the CLCP policy on economic growth based on the calculated trend score. The specific results are shown in Table 5. It can be seen from Table 4 that the CLCP policy still has a significant promoting effect on regional economic growth. The results of the robustness test by using PSM-DID can effectively overcome the bias of policy evaluation results caused by systematic differences between the 
treatment group and the control group, which also indirectly proves that the results in Table 3 have good robustness.

Table 5: PSM-DID robustness test

\begin{tabular}{|c|c|c|c|c|c|c|c|}
\hline & $\begin{array}{l}\text { Prepilot } \\
\text { Treatment } \\
\text { Group }\end{array}$ & $\begin{array}{l}\text { Prepilot } \\
\text { Control } \\
\text { Group }\end{array}$ & $\begin{array}{c}\text { Differences between Prepilot } \\
\text { Control Group and Prepilot } \\
\text { Treatment Group }\end{array}$ & $\begin{array}{l}\text { Postpilot } \\
\text { Treatment } \\
\text { Group }\end{array}$ & $\begin{array}{l}\text { Postpilot } \\
\text { Control } \\
\text { Group }\end{array}$ & $\begin{array}{c}\text { Differences between } \\
\text { Postpilot Control Group } \\
\text { and Postpilot Treatment } \\
\text { Group }\end{array}$ & $\begin{array}{c}\text { DID Test } \\
\text { Results }\end{array}$ \\
\hline gdp & 15.301 & 15.087 & 0.213 & 15.063 & 15.216 & 0.153 & 0.169 \\
\hline standard error & & & 0.077 & & & 0.062 & 0.059 \\
\hline t Value & & & 2.77 & & & 2.46 & 2.88 \\
\hline $\mathrm{p}>|\mathrm{t}|$ & & & $0.000^{* * *}$ & & & $0.000^{* *}$ & $0.000^{* * *}$ \\
\hline pergdp & 9.469 & 9.297 & 0.172 & 9.15 & 9.326 & 0.176 & 0.175 \\
\hline standard error & & & 0.066 & & & 0.058 & 0.053 \\
\hline t Value & & & 2.63 & & & 3.07 & 3.28 \\
\hline $\mathrm{p}>|\mathrm{t}|$ & & & $0.000 * * *$ & & & $0.000 * * *$ & $0.000^{* * *}$ \\
\hline
\end{tabular}

Note: $(1)^{*}, * *$, and $* * *$ indicate significance at the confidence levels of $10 \%, 5 \%$, and $1 \%$, respectively.

\subsubsection{Removal of the samples with heterogeneity}

In addition to the parallel trend test, the imbalance of regional economic development may also cause great differences among the selected samples. The differences may cause the parallel trend hypothesis to be questioned and produce bias in the model's evaluation results. To solve this problem, eastern and western cities are eliminated from the sample in this article to reduce the differences among the samples. The reason for choosing the eastern and western regions is that there is a large imbalance between the east and west in China's economic development. Removing the two extreme samples of economic development can allow a better comparison to ensure the robustness of the results. The specific regression results are shown in Table 6 . In Table 6, Columns (1)-(4) are the regression results after culling the samples from the eastern regions, while Columns (5)-(8) are the regression results after culling the samples from the western regions. It can be seen from the table that the elimination of the eastern sample does not change the promoting effect of the CLCP policy on regional economic growth. The effect was significant at a confidence level of $1 \%$ for both regional and per capital GDP. By comparing the regression results in Tables 6 and 3, it can be seen that although the effect of the CLCP policy on economic growth varies, the fluctuation range is relatively small, which further illustrates the robustness of the regression results in Table 3.

In addition, in order to further exclude the influence of sample difference, we excluded economically developed cities, namely Shenzhen, Xiamen and Hangzhou, from the pilot cities, so as to compare other cities. In addition, we excluded some cities with higher political influence and better institutions than other cities, such as Beijing, Shanghai and so on. The specific regression results are shown in Table 7. Among them, the Columns (1)-(4) are mainly 
the regression results after removing Shenzhen, Xiamen and Hangzhou, while the Columns (5)(8) are the regression results after excluding Beijing, Shanghai, Tianjin, Chongqing, Shenzhen, Hangzhou and Xiamen. It can be seen that sample exclusion has not changed the promotion effect of CLCP policy on economic growth, which further consolidated and strengthened research conclusions of this study.

Table 6: Removal of the samples with regional heterogeneity

\begin{tabular}{|c|c|c|c|c|c|c|c|c|}
\hline & \multicolumn{2}{|c|}{ gdp } & \multicolumn{2}{|c|}{ pergdp } & \multicolumn{2}{|c|}{ gdp } & \multicolumn{2}{|c|}{ pergdp } \\
\hline & (1) & (2) & (3) & (4) & (5) & (6) & (7) & (8) \\
\hline \multirow[t]{2}{*}{ Pilot $\times$ Time } & $0.020^{* * *}$ & $0.020^{* * *}$ & $0.035^{* * *}$ & $0.056^{* * *}$ & $0.033^{* * *}$ & $0.028 * * *$ & $0.039 * * *$ & $0.042^{* * *}$ \\
\hline & $(0.007)$ & $(0.006)$ & $(0.008)$ & $(0.008)$ & $(0.006)$ & $(0.005)$ & $(0.007)$ & $(0.007)$ \\
\hline Control variables & NO & YES & NO & YES & NO & YES & NO & YES \\
\hline Individual fixed effects & YES & YES & YES & YES & YES & YES & YES & YES \\
\hline Time fixed effects & YES & YES & YES & YES & YES & YES & YES & YES \\
\hline \multirow[t]{2}{*}{ _cons } & $14.049^{* * *}$ & $12.925^{* * *}$ & $8.344^{* * *}$ & $7.546 * * *$ & $14.455^{* * *}$ & $13.270^{* * *}$ & $8.590^{* * *}$ & $7.691^{* * *}$ \\
\hline & $(0.005)$ & $(0.084)$ & $(0.007)$ & $(0.117)$ & $(0.004)$ & $(0.067)$ & $(0.006)$ & $(0.101)$ \\
\hline $\mathrm{N}$ & 2,548 & 2,414 & 2,538 & 2,414 & 2,860 & 2,822 & 2,852 & 2,822 \\
\hline $\mathrm{F}$ & $8,293.464$ & $7,659.366$ & $4,401.176$ & $3,445.904$ & $11,729.392$ & $11,774.172$ & $5,779.939$ & $4,537.172$ \\
\hline r2 & 0.979 & 0.986 & 0.961 & 0.969 & 0.983 & 0.989 & 0.966 & 0.972 \\
\hline
\end{tabular}

Note: (1) The values in brackets are standard errors; (2) *, **, and *** indicate significance at the confidence levels of $10 \%, 5 \%$, and $1 \%$, respectively.

Table 7: Evaluation results after excluding sample differences

\begin{tabular}{cccccccccc}
\hline & \multicolumn{2}{c}{ gdp } & \multicolumn{2}{c}{ pergdp } & \multicolumn{2}{c}{ gdp } & \multicolumn{2}{c}{ pergdp } \\
& $\mathbf{( 1 )}$ & $\mathbf{( 2 )}$ & $\mathbf{( 3 )}$ & $\mathbf{( 4 )}$ & $\mathbf{( 5 )}$ & $\mathbf{( 6 )}$ & $\mathbf{( 7 )}$ & $\mathbf{( 8 )}$ \\
\hline Pilot $\times$ Time & $0.028^{* * *}$ & $0.020^{* * *}$ & $0.043^{* * *}$ & $0.039 * * *$ & $0.027 * * *$ & $0.020^{* * *}$ & $0.042^{* * *}$ & $0.040^{* * *}$ \\
& $(0.006)$ & $(0.005)$ & $(0.007)$ & $(0.007)$ & $(0.006)$ & $(0.005)$ & $(0.008)$ & $(0.007)$ \\
Control variables & NO & YES & NO & YES & NO & YES & NO & YES & YES \\
Individual fixed effects & YES & YES & YES & YES & YES & YES & YES & YES \\
Time fixed effects & YES & YES & YES & YES & YES & YES & YES & Y.573** \\
Cons & $14.296 * * *$ & $13.139 * * *$ & $8.501 * * *$ & $7.562 * * *$ & $14.280 * * *$ & $13.137 * * *$ & $8.497 * * *$ & $7.573 * * *$ \\
N & $(0.004)$ & $(0.068)$ & $(0.005)$ & $(0.094)$ & $(0.004)$ & $(0.068)$ & $(0.006)$ & $(0.095)$ \\
F & 3315 & 3179 & 3304 & 3179 & 3289 & 3153 & 3278 & 3153 \\
r2 & 12174.301 & 11506.871 & 6570.508 & 5190.973 & 12019.508 & 11339.358 & 6473.836 & 5109.906 \\
\hline
\end{tabular}

Note: (1) The values in brackets are standard errors; (2) *, **, and *** indicate significance at the confidence levels of $10 \%, 5 \%$, and $1 \%$, respectively. 


\subsubsection{Endogenous problem}

Although the above removal of samples with large differences can alleviate the differences between cities to a certain extent and avoid bias of policy implementation caused by urban differences.

Unfortunately, not all factors can be eliminated, such as the regional environmental regulation system, which is not only difficult to measure, but also an important factor affecting regional carbon emissions and economic growth. Cities with a perfect environmental regulation system have a lower carbon emission, so the probability of being selected as a carbon pilot city is lower. Otherwise, cities with imperfect environmental regulations system have higher carbon emissions and are more likely to implement CLCP policy. The endogenous problems caused by the environmental regulation system cannot be eliminated by sample exclusion. In order to further thoroughly solve this endogenous problem, we adopt instrumental variables method here.

Instrumental variables selection needs to satisfy two conditions: high correlation with explanatory variables and no correlation with random disturbance terms. In view of this, we started from the conditions for CLCP policy implementation. As the CLCP policy is implemented in a region with high carbon emission, the original carbon emission of the region determines whether the city can become a CLCP city. The carbon emission of the region is directly related to the economic development of the region, so we take the rainfall, sunshine time and wind speed of each region as the instrumental variables of whether the region becomes a CLCP city or not. The reasons are as follows: the above factors are closely related to the early agricultural economic development of each region. The more developed the agricultural economy is, the earlier it enters the industrialization era. The higher the industrialization level can lead to higher carbon emissions in region, the higher the probability that this region is selected as a CLCP city, and vice versa. However, these factors have had little impact on modern economic growth. Therefore, these variables meet the basic requirements of instrumenttal variables. The specific regression results are shown in Table 8. It can be seen that after using instrumental variables to deal with endogenous problems, CLCP policy still significantly promotes regional economic growth. Moreover, it can also be seen from the regression results of the first stage that instrumental variables constructed in terms of rainfall, sunshine time and wind speed are significantly positively correlated with the CLCP cities selection, which is also in line with the expectations of instrumental variable selection.

\subsubsection{Counterfactual Test}

Are other random factors influencing the promotion effect of the CLCP policy on economic growth? This article uses regional counterfactuals to eliminate this problem and answer this question. Therefore, half of the samples are randomly selected from both the sample population and the control group as the hypothetical treatment group, and the imaginary effect is estimated by using the DID method. If the significant effect is the same as the real result, it indicates that other random factors influence the evaluation results in this article. In the contrary situation, no random factor interferes with the effect of the CLCP policy on economic growth. The specific results are shown in Table 9. Columns (1)-(4) in Table 9 are the regression results of randomly selected samples in the entire sample as the hypothetical treatment group (random1), while 
Columns (5)-(8) in Table 9 are the regression results of randomly selected samples in the control group as the hypothetical treatment group (random2). It can be seen from the regression results that no significant effect is obtained, which indicates that no other random factors influence the results in this article. This finding further proves that the promotion effect of the CLCP policy on economic growth is not caused by other random factors.

\subsubsection{Elimination of policy interference}

Although the above tests have further guaranteed the reliability of the evaluation results in this article, due to the complexity of the real social system, the implementation of any economic policy is inevitably affected by other policies or historical shocks, which potentially affects the evaluation of policy effects. Therefore, a series of policy shocks that affect economic growth are excluded in this section to ensure the robustness of the estimated results in this article. The specific test process is as follows. First, considering the fluctuations of China's economic growth affected by the global financial crisis in 2008, we compress the time period from 2008 to 2011 by excluding the years before the financial crisis and then compare the samples after the financial crisis to obtain the net effect. The specific results are shown in Columns (1) and (2) in Table 10. The results show that the CLCP policy still has a significant promoting effect on economic growth when the impact of financial crisis is removed. Second, considering China's reform of the exchange rate system in 2005, the exchange rate reform is bound to affect the inflow

Table 8: The impact of CLCP policy on regional economic growth: instrumental variable

\begin{tabular}{ccccc}
\hline & \multicolumn{2}{c}{ gdp } & \multicolumn{2}{c}{ pergdp } \\
\cline { 2 - 5 } & $\mathbf{( 1 )}$ & $\mathbf{( 2 )}$ & $\mathbf{( 3 )}$ & $\mathbf{( 4 )}$ \\
\hline Pilot $\times$ Time & $0.256^{* *}$ & $0.523^{* *}$ & $0.379^{* * *}$ & $0.770^{* *}$ \\
& $(0.109)$ & $(0.253)$ & $(0.145)$ & $(0.361)$ \\
Control variables & NO & YES & NO & YES \\
Individual fixed effects & YES & YES & YES & YES \\
Time fixed effects & YES & YES & YES & YES \\
N & 1742 & 1655 & 1738 & 1655 \\
F & 4240.389 & 1381.933 & 2090.773 & 596.347 \\
r2 & 0.969 & 0.941 & 0.938 & 0.865 \\
\hline iv & & First-Stage & & \\
& $0.002^{* * *}$ & $0.001^{* * *}$ & $0.002^{* * *}$ & $0.001^{* * *}$ \\
Cragg-Donald Wald $\mathrm{F}$ & $(0.000)$ & $(0.001)$ & $(0.000)$ & $(0.001)$ \\
\hline
\end{tabular}

Note: (1) The values in brackets are standard errors; (2) *, **, and *** indicate significance at theconfidence levels of $10 \%, 5 \%$, and $1 \%$, respectively. 
Table 9: Counterfactual test

\begin{tabular}{ccccccccc}
\hline & \multicolumn{2}{c}{ gdp } & \multicolumn{2}{c}{ pergdp } & \multicolumn{2}{c}{ gdp } & \multicolumn{2}{c}{ pergdp } \\
& $\mathbf{( 1 )}$ & $\mathbf{( 2 )}$ & $\mathbf{( 3 )}$ & $\mathbf{( 4 )}$ & $\mathbf{( 5 )}$ & $\mathbf{( 6 )}$ & $\mathbf{( 7 )}$ & $\mathbf{( 8 )}$ \\
\hline random1 & 0.004 & 0.003 & 0.002 & 0.002 & & & & \\
& $(0.004)$ & $(0.004)$ & $(0.006)$ & $(0.005)$ & & & & \\
random2 & & & & & -0.002 & -0.005 & -0.004 & -0.006 \\
& & & & & $(0.005)$ & $(0.004)$ & $(0.006)$ & $(0.005)$ \\
Control variables & NO & YES & NO & YES & NO & YES & NO & YES \\
Individual fixed effects & YES & YES & YES & YES & YES & YES & YES & YES \\
Time fixed effects & YES & YES & YES & YES & YES & YES & YES & YES \\
_cons & $14.317 * * *$ & $13.156 * * *$ & $8.526 * * *$ & $7.559 * * *$ & $14.317 * * *$ & $13.154 * * *$ & $8.526 * * *$ & $7.558^{* * *}$ \\
& $(0.004)$ & $(0.068)$ & $(0.006)$ & $(0.097)$ & $(0.004)$ & $(0.068)$ & $(0.006)$ & $(0.097)$ \\
N & 3,354 & 3,218 & 3,343 & 3,218 & 3354 & 3218 & 3343 & 3218 \\
F & $12,301.189$ & $11,578.750$ & $6,382.972$ & $4,977.314$ & 12299.058 & 11584.736 & 6383.940 & 4979.079 \\
r2 & 0.981 & 0.987 & 0.964 & 0.971 & 0.981 & 0.987 & 0.964 & 0.971 \\
\hline
\end{tabular}

Note: (1) The values in brackets are standard errors; $(2) * * *$, and *** indicate significance at the confidence levels of $10 \%$, $5 \%$, and $1 \%$, respectively.

of foreign capital and import and export trade. Accordingly, evaluation results that cannot effectively eliminate the interference of this policy are biased. Therefore, this article selected the investigation period from 2007 to 2012 for evaluation and analysis. The specific results are shown in Columns (3) and (4) in Table 10. It can be seen that policy exclusion does not affect the significant promoting effect of the CLCP policy on economic growth. Third, the CLCP policy was implemented in 2010, but the investigation period selected in this article was set from 2001 to 2013. Considering that the imbalance of the investigation period before and after the implementation of the policy may lead to doubt in the evaluation results, this article sets the investigation period from 2006 to 2013 to maintain the balance of the time before and after the implementation of the policy. The specific results are shown in Columns (5) and (6) in Table 10. The results show that the change of investigation period does not affect the significant promoting effect of the CLCP policy on regional economic growth. Thus, compared with the results in Table 3, the exclusion of policy interference did not make the evaluation coefficient fluctuate significantly. Therefore, the results in Table 10 strongly demonstrate that the choice of study period does not affect the policy effect evaluated in this article and further show the robustness of the above results. 
Table 10: Elimination of policy interference: change time window

\begin{tabular}{|c|c|c|c|c|c|c|}
\hline & \multicolumn{2}{|c|}{$2007<$ year $<2012$} & \multicolumn{2}{|c|}{$2006<$ year $<2013$} & \multicolumn{2}{|c|}{$2005<$ year $<2014$} \\
\hline & $\begin{array}{l}\text { gdp } \\
(1)\end{array}$ & $\begin{array}{c}\text { pergdp } \\
(2) \\
\end{array}$ & $\begin{array}{l}\text { gdp } \\
(3)\end{array}$ & $\begin{array}{c}\text { pergdp } \\
(4) \\
\end{array}$ & $\begin{array}{l}\text { gdp } \\
(5)\end{array}$ & $\begin{array}{c}\text { pergdp } \\
(6) \\
\end{array}$ \\
\hline Pilot $\times$ Time & $\begin{array}{c}0.012 * * * \\
(0.003)\end{array}$ & $\begin{array}{c}0.018^{* * *} \\
(0.005)\end{array}$ & $\begin{array}{c}0.016^{* * *} \\
(0.003)\end{array}$ & $\begin{array}{c}0.024 * * * \\
(0.005)\end{array}$ & $\begin{array}{c}0.019 * * * \\
(0.004)\end{array}$ & $\begin{array}{c}0.030 * * * \\
(0.005)\end{array}$ \\
\hline Control variables & YES & YES & YES & YES & YES & YES \\
\hline Individual fixed effects & YES & YES & YES & YES & YES & YES \\
\hline Time fixed effects & YES & YES & YES & YES & YES & YES \\
\hline _cons & $\begin{array}{c}14.728 * * * \\
(0.106)\end{array}$ & $\begin{array}{c}9.221^{* * *} \\
(0.182)\end{array}$ & $\begin{array}{c}14.359 * * * \\
(0.088)\end{array}$ & $\begin{array}{c}8.766^{* * *} \\
(0.133)\end{array}$ & $\begin{array}{c}14.003^{* * *} \\
(0.084)\end{array}$ & $\begin{array}{c}8.473^{* * *} \\
(0.115)\end{array}$ \\
\hline $\mathrm{N}$ & 996 & 996 & 1,494 & 1,494 & 1,992 & 1,992 \\
\hline $\mathrm{F}$ & $4,032.311$ & $1,165.957$ & $6,359.920$ & $2,434.957$ & $8,061.100$ & $3,742.317$ \\
\hline r2 & 0.984 & 0.946 & 0.985 & 0.963 & 0.986 & 0.970 \\
\hline
\end{tabular}

Note: (1) The values in brackets are standard errors; $(2)^{*}, * *$, and *** indicate significance at the confidence levels of $10 \%, 5 \%$, and $1 \%$, respectively.

\subsubsection{Adding covariates test}

The results of the above tests indicate that the CLCP policy has a significant and steady promoting effect on regional economic development. However, considering that omitted variables may cause bias in the evaluation results, to further control the factors at the district level, this article refers to the practice of Moser and Voena (2012) to add the change trend of the region over time and the interaction term of the region dummy variable and year dummy variable (district-by-year) based on model (1). At the same time, considering the problem of freedom, this article does not address it directly at the prefecture level but at the provincial level. Specifically, we separately added the interaction term of the province dummy variable and year dummy variable $\gamma_{p} \times \delta_{t}$, primary variable of a province over time $\gamma_{p} \times t$ (t=year-2001) and quadratic variable of a province over time $\gamma_{p} \times t^{2}$ in the model to control the nonlinear trend changes of economic growth in different regions, which makes the results evaluated by the DID method more convincing. The specific results are shown in Table 11. Columns (1)- (4) in Table 11 are the regression results of the model after adding the interaction terms of region and time, and Columns (5)-(8) in Table 11 are the regression results of the model after adding the primary and quadratic variables of a province over time. It can be seen from the results that considering regional and time factors, the CLCP policy still has a significant promoting effect on economic growth. However, compared with the evaluation effect in Table 3, the evaluation coefficient in Table 11 decreases slightly. 
Table 11: Adding covariates test

\begin{tabular}{|c|c|c|c|c|c|c|c|c|}
\hline & \multicolumn{2}{|c|}{ gdp } & \multicolumn{2}{|c|}{ pergdp } & \multicolumn{2}{|c|}{ gdp } & \multicolumn{2}{|c|}{ pergdp } \\
\hline & (1) & (2) & (3) & (4) & (5) & (6) & (7) & (8) \\
\hline \multirow[t]{2}{*}{ Pilot $\times$ Time } & $0.022 * * *$ & $0.011^{*}$ & $0.018^{*}$ & $0.016^{*}$ & $0.015^{* * *}$ & $0.015^{* * *}$ & $0.030 * * *$ & $0.030 * * *$ \\
\hline & $(0.007)$ & $(0.006)$ & $(0.010)$ & $(0.009)$ & $(0.005)$ & $(0.005)$ & $(0.007)$ & $(0.007)$ \\
\hline Control variables & NO & YES & NO & YES & YES & YES & YES & YES \\
\hline$\gamma_{p} \times \delta_{t}$ & YES & YES & YES & YES & NO & NO & NO & NO \\
\hline$\gamma_{p} \times t$ & NO & NO & NO & NO & YES & YES & YES & YES \\
\hline$\gamma_{p} \times t^{2}$ & NO & NO & NO & NO & NO & YES & NO & YES \\
\hline Individual fixed effects & YES & YES & YES & YES & YES & YES & YES & YES \\
\hline Time fixed effects & YES & YES & YES & YES & YES & YES & YES & YES \\
\hline \multirow[t]{2}{*}{ _cons } & $-228.512 * * *$ & $-193.177^{* * *}$ & $-217.829 * * *$ & $-181.233^{* * *}$ & $13.234 * * *$ & $13.234 * * *$ & $7.655^{* * *}$ & $7.658 * * *$ \\
\hline & $(0.872)$ & (2.393) & (1.147) & (3.422) & $(0.068)$ & $(0.068)$ & $(0.097)$ & $(0.097)$ \\
\hline $\mathrm{N}$ & 3,354 & 3,218 & 3,343 & 3,218 & 3,218 & 3,218 & 3,218 & 3,218 \\
\hline F & $5,907.623$ & 7,309.502 & 2,993.642 & $3,108.212$ & $7,217.757$ & $5,165.889$ & $3,085.538$ & 2,207.124 \\
\hline r2 & 0.988 & 0.992 & 0.976 & 0.981 & 0.988 & 0.988 & 0.972 & 0.972 \\
\hline
\end{tabular}

Note: (1) The values in brackets are standard errors; (2)*, **, and *** indicate significance at the confidence levels of $10 \%, 5 \%$, and $1 \%$, respectively.

\section{Further analysis: source of economic growth?}

The above analysis strongly proves that the CLCP policy has significantly promoted the economic growth at the regional level, and the promoting effect has good robustness. However, only analyzing the economic benefits of the CLCP policy at the macrolevel does not effectively and intuitively explain its internal mechanism. To test the internal mechanism of the policy effect, this article investigates the impact of the implementation of the CLCP policy on enterprise behavior from the perspective of microenterprises and uses this as the microbasis for the conclusions obtained at the macrolevel. There are two reasons why this study chooses the perspective of the enterprise, and the details are as follows. First, the microcosmic reflection of regional economic development is the growth of enterprise output. An analysis of enterprise output is conducted not only to further consolidate and confirm the conclusions of the above macroanalysis but also to deepen the understanding of the CLCP policy's effect on economic growth. Second, environmental regulation mainly affects enterprise income by influencing enterprise behavior and decision-making, and then it changes the overall output level of the region. Therefore, microenterprise data provide a good opportunity to solve this problem.

In order to make analysis in this part more rigorous, from the perspective of enterprise behavior, we carefully sort out influence mechanism of CLCP policy as an important environmental regulation policy, and draw the following Figure 5. It can be seen that CLCP 
policy implementation increases enterprises' production cost in CLCP areas, which makes them unable to bear, especially for those pollution-intensive enterprises. The loss of production advantage forces enterprises to transfer, so as to avoid the profit loss caused by external cost increase. However, transfer also can produce the huge additional cost. Therefore, more and more enterprises choose to improve productivity, strengthen enterprise management and technology innovation to overcome production cost increase, so as to offset the negative impact of CLCP policies on enterprise output, and thus achieve output expansion and economic growth. This internal mechanism is the logic chain of the micro part of the analysis.

Figure 5: The mechanism of LCP policy affecting economic growth

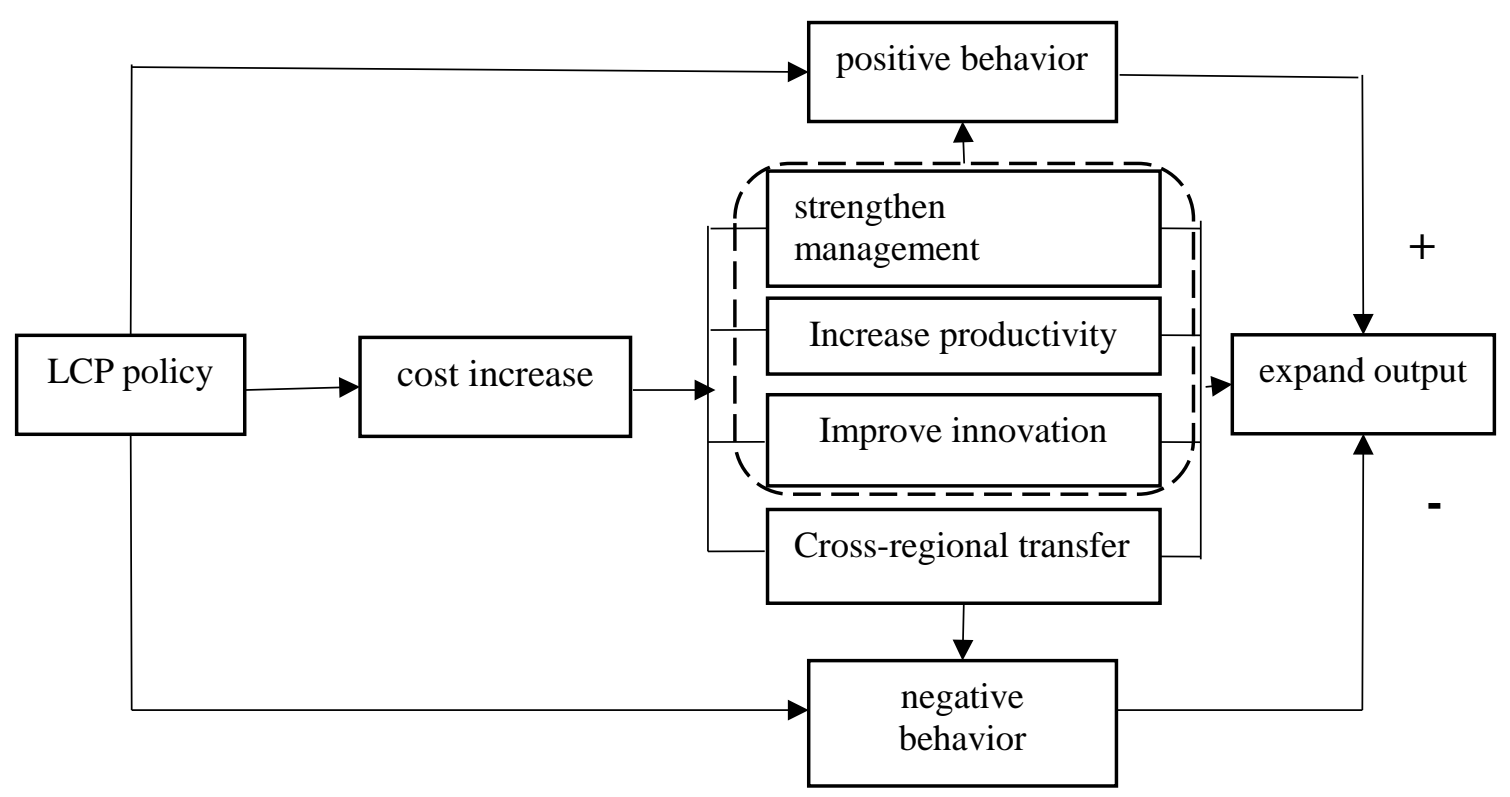

\subsection{The impact of the CLCP policy on the costs and benefits of enterprises}

\subsubsection{The impact of the CLCP policy on enterprise benefits}

From the macroanalysis, it can be seen that the CLCP policy can significantly promote regional economic growth and has a lasting impetus. Does this significant promotion effect also exist at the enterprise level? This section mainly answers this question. Under the premise of data availability, this article selects the logarithm of main business income (income), the logarithm of enterprise operating revenue (revenue) and the logarithm of enterprise total profit (profit) to measure enterprise output and income and then uses the DID method to evaluate the results at the microlevel. The specific results are shown in Columns (1)-(3) in Table 12. At the same time, considering the interference of other macro-policies, this study excludes the year of investigation. The regression results after elimination are shown in Columns (4)-(6) in Table 12. The regression results show that the implementation of the CLCP policy promotes the benefits of enterprises, and the effect is significant at the $1 \%$ confidence level, regardless of 
which indicator is used to measure enterprise output or the division of the investigation period. At the same time, evaluation results in Table 12 are completely consistent with the analysis results in Table 3 on the macrolevel, which fully shows that the increase of output at the enterprise level is the microbasis for economic growth at the regional level.

Table 12: The impact of the CLCP policy on enterprise benefits

\begin{tabular}{|c|c|c|c|c|c|c|}
\hline & \multicolumn{3}{|c|}{$2001<$ year $<2014$} & \multicolumn{3}{|c|}{$2005<$ year $<2014$} \\
\hline & $\begin{array}{c}\text { income } \\
(1)\end{array}$ & $\begin{array}{c}\text { revenue } \\
\text { (2) }\end{array}$ & $\begin{array}{c}\text { profit } \\
(3)\end{array}$ & $\begin{array}{c}\text { income } \\
(4)\end{array}$ & $\begin{array}{c}\text { revenue } \\
\text { (5) }\end{array}$ & $\begin{array}{c}\text { profit } \\
(6)\end{array}$ \\
\hline Pilot $\times$ Time & $\begin{array}{c}0.129 * * * \\
(0.003)\end{array}$ & $\begin{array}{c}0.141^{* * *} \\
(0.010)\end{array}$ & $\begin{array}{c}0.083 * * * \\
(0.010)\end{array}$ & $\begin{array}{c}0.088^{* * *} \\
(0.003)\end{array}$ & $\begin{array}{c}0.112 * * * \\
(0.010)\end{array}$ & $\begin{array}{c}0.065^{* * *} \\
(0.010)\end{array}$ \\
\hline Control variables & YES & YES & YES & YES & YES & YES \\
\hline Individual fixed effects & YES & YES & YES & YES & YES & YES \\
\hline Time fixed effects & YES & YES & YES & YES & YES & YES \\
\hline _cons & $\begin{array}{c}3.053^{* * *} \\
(0.016)\end{array}$ & $\begin{array}{c}-1.256^{* * *} \\
(0.048)\end{array}$ & $\begin{array}{c}-2.385 * * * \\
(0.048)\end{array}$ & $\begin{array}{c}3.547 * * * \\
(0.023)\end{array}$ & $\begin{array}{c}-0.860 * * * \\
(0.068)\end{array}$ & $\begin{array}{c}-2.338 * * * \\
(0.068)\end{array}$ \\
\hline $\mathrm{N}$ & 600147 & 455595 & 460422 & 391015 & 303743 & 305244 \\
\hline $\mathrm{F}$ & 27015.178 & 3784.588 & 3873.001 & 16022.011 & 2512.618 & 3148.516 \\
\hline r2 & 0.499 & 0.162 & 0.163 & 0.415 & 0.131 & 0.159 \\
\hline
\end{tabular}

Note: (1) The values in brackets are standard errors; $(2) *, * *$, and *** indicate significance at the confidence levels of $10 \%, 5 \%$, and $1 \%$, respectively.

\subsubsection{The impact of the CLCP policy on enterprise costs}

In Table 12, it can be seen that the implementation of the CLCP policy does not reduce enterprise performance, but significantly increases the enterprise output and income. The conclusion seems to indicate that environmental regulation has no negative impact on enterprises. However, in fact, compared with the absence of environmental constraints, environmental constraints have significantly changed the production costs of enterprises. This increased cost affects macroeconomic growth by changing enterprise behavior and decision-making. To conduct a detailed empirical test of enterprise cost, this article uses product sales tax and surcharge (salestax), product sales expenses (salesfee), enterprise payable VAT (tax), enterprise payable income tax (paytax) and enterprise payable total wages (wage) to measure the various costs of enterprises. There are two reasons for choosing sales costs and taxes. On the one hand, due to environmental regulation, enterprises' environmental pollution emissions standards become higher, which increases enterprises' production costs by increasing enterprises' additional costs. On the other hand, in the process of environmental governance, local governments change the previous subsidies and preferential policies for enterprises, which has a significant impact on the tax level of enterprises. The specific results are shown in Table 13. It can be seen from Columns (1)-(4) in Table 13 that although the implementation of the CLCP policy causes the growth 
degree of different types of costs of enterprises to vary, it is undeniable that the policy significantly increases the production costs of enterprises. This is largely because of the additional costs associated with the level of technology, tax reduction and exemption and policy tilt required by environmental regulations. Column (5) in Table 13 shows that the CLCP policy reduces the wage costs payable by enterprises, and the effect is significant at the $1 \%$ confidence level, which indicates that enterprises have adjusted their internal management and personnel structure, eliminated surplus personnel and strengthened management to respond to the external pressure from environmental regulation. Overall, the implementation of the CLCP policy significantly increases the production costs of enterprises.

Table 13: The impact of the CLCP policy on enterprise costs

\begin{tabular}{cccccc}
\hline & salestax & salesfee & tax & paytax & wage \\
& $(\mathbf{1})$ & $\mathbf{( 2 )}$ & $\mathbf{( 3 )}$ & $\mathbf{( 4 )}$ & $\mathbf{( 5 )}$ \\
\hline Pilot $\times$ Time & $0.071^{* * *}$ & $0.032^{*}$ & $0.410^{* * *}$ & $0.136 * * *$ & $-0.035^{* * *}$ \\
& $(0.020)$ & $(0.018)$ & $(0.009)$ & $(0.012)$ & $(0.005)$ \\
Control variables & YES & YES & YES & YES & YES \\
Individual fixed effects & YES & YES & YES & YES & YES \\
Time fixed effects & YES & YES & YES & YES & YES \\
_cons & $-1.683^{* * *}$ & $-1.171^{* * *}$ & 0.039 & $-5.265 * * *$ & $1.404^{* * *}$ \\
& $(0.100)$ & $(0.085)$ & $(0.046)$ & $(0.070)$ & $(0.020)$ \\
N & 145332 & 136359 & 456541 & 289017 & 457387 \\
F & 717.793 & 2432.103 & 3181.926 & 3544.592 & 30519.967 \\
r2 & 0.103 & 0.288 & 0.139 & 0.235 & 0.576 \\
\hline
\end{tabular}

Note: (1) The values in brackets are standard errors; $(2) *, * *$, and *** indicate significance at the confidence levels of $10 \%, 5 \%$, and $1 \%$, respectively.

\subsection{The impact of the CLCP policy on enterprise decision-making}

The cost-benefit analysis of enterprises shows that although the CLCP policy increases the production costs of enterprises, it does not cause the decline of enterprise output and performance. In contrast, this policy has a significant promoting effect on enterprise performance. What strategies do enterprises adopt to cope with the cost pressure brought by environmental regulations while also improving their performance? Answering this question helps not only to further explore the internal mechanism of the impact of the CLCP policy on economic growth but also to have a deeper understanding of the enterprise strategy selection under changes of the external environment, which further provides a more comprehensive analysis of the economic benefits of the CLCP policy. Therefore, from the perspective of the specific behaviors of enterprises, this article respectively examines the impact of CLCP policies on the trans-regional transfer, management, efficiency and innovation activities of enterprises. The reasons for choosing these three major enterprise behaviors are as follows. As a means of environmental regulation, the implementation of CLCP policy inevitably raises the production costs of microenterprises and forces them to adopt positive strategies to manage the increase of costs. 
How should managers make decisions to improve business performance in this context? For this, there are two strategies for enterprises. First, enterprises can reduce costs by adopting innovative activities such as improving production processes and cleaner production standards to create opportunities for enterprises to survive. Enterprises move directly from CLCP areas to non-pilot areas to reduce the negative impact of the increased costs caused by environmental constraints on enterprises. The specific analysis follows.

\subsubsection{The impact of the CLCP policy on enterprise migration}

Compared with non-pilot regions, enterprises in pilot regions are regulated by environmental governance. The results in Table 13 also show that the environmental regulations increase the production costs of enterprises. To cope with the increase of production costs, do enterprises adopt the strategy of trans-regional transfer to avoid the cost repression that is caused by environmental regulations, that is, from low-carbon pilot areas to non-pilot areas? Then, the next question to consider is whether there is a "pollution paradise hypothesis" among regions. If it is true, the transfer of pollution enterprises caused by environmental regulations will lead to severe sample selection bias that will affect the net effect estimation of the above policy evaluation. To conduct an empirical test for the rational behavior of enterprises, this study selects the number of new enterprises whose age is less than one year (firmnumber0) and the number of new enterprises aged one year (firmnumber1) in each region to measure the enterprise transfer behavior. If the CLCP policy leads to the cross-regional transfer of enterprises, then the CLCP policy has a significant impact on the number of new enterprises. Otherwise, there is no cross-regional transfer. The specific results are shown in Table 14. It can be seen from the regression results that the implementation of the CLCP policy has no significant impact on the number of newly established foreign-funded enterprises. This result indicates that environmental regulation has not led to the cross-regional transfer of enterprises. It also shows that environmental regulation has no obvious effect on enterprises' settling in this area, that is, there is no factual basis for "pollution paradise hypothesis" and the empirical dilemma of sample self-selection. The most reasonable explanation is the transfer cost and silence cost of enterprise transfer, which forces enterprises to adopt more rational choices to manage the external pressure and cost increase brought by environmental regulations.

\subsubsection{Impact of the CLCP policy on enterprise management efficiency}

Under the pressure of a significant increase in production costs, enterprises do not choose crossregional transfer to avoid the trouble caused, so how can enterprises realize the benefit enhancement? Column (5) in Table 13 indicates that the CLCP policy implementation does not increase the wage costs but rather reduces these costs. It can be seen that under the constraint of environmental regulation, enterprises choose methods such as strengthening management, improving operation and improving efficiency to relieve external pressure. To conduct a powerful empirical test for this, this article selects management costs (managemcosts) to measure 
Economics: The Open-Access, Open-Assessment E-Journal 13 (2019-47)

Table 14: The impact of the CLCP policy on enterprise migration

\begin{tabular}{|c|c|c|c|c|c|c|}
\hline & \multicolumn{3}{|c|}{ firmnumber0 } & \multicolumn{3}{|c|}{ firmnumber1 } \\
\hline & (1) & (2) & (3) & (4) & (5) & (6) \\
\hline \multirow[t]{2}{*}{ Pilot $\times$ Time } & 0.248 & 0.129 & 0.399 & 0.958 & 1.308 & 2.552 \\
\hline & $(0.955)$ & $(0.962)$ & $(0.985)$ & (2.303) & (2.313) & (2.371) \\
\hline \multirow[t]{2}{*}{ investment } & & $2.327 * * *$ & $3.068 * * *$ & & $9.881^{* * *}$ & $9.713^{* * *}$ \\
\hline & & $(0.784)$ & $(0.928)$ & & (1.885) & (2.233) \\
\hline \multirow[t]{2}{*}{ labor } & & $2.600 * *$ & $2.859 * *$ & & 2.365 & $5.161^{*}$ \\
\hline & & (1.066) & (1.226) & & (2.564) & (2.951) \\
\hline \multirow[t]{2}{*}{ government } & & -0.013 & $-0.138 * * *$ & & 0.014 & -0.135 \\
\hline & & $(0.031)$ & $(0.047)$ & & $(0.074)$ & $(0.113)$ \\
\hline \multirow[t]{2}{*}{ open } & & & 0.053 & & & 0.329 \\
\hline & & & $(0.108)$ & & & $(0.259)$ \\
\hline \multirow[t]{2}{*}{ industry } & & & 0.023 & & & 0.100 \\
\hline & & & $(0.056)$ & & & $(0.134)$ \\
\hline \multirow[t]{2}{*}{ education } & & & -0.000 & & & $-0.000 * * *$ \\
\hline & & & $(0.000)$ & & & $(0.000)$ \\
\hline \multirow[t]{2}{*}{ save } & & & $5.655^{* * *}$ & & & $8.794 * * *$ \\
\hline & & & $(0.927)$ & & & $(2.230)$ \\
\hline $\begin{array}{l}\text { Individual fixed } \\
\text { effects }\end{array}$ & YES & YES & YES & YES & YES & YES \\
\hline Time fixed effects & YES & YES & YES & YES & YES & YES \\
\hline \multirow[t]{2}{*}{ _cons } & $1.900^{* * *}$ & $-37.459 * * *$ & $-50.696 * * *$ & $6.419 * * *$ & $-132.147 * * *$ & $-146.438 * * *$ \\
\hline & $(0.644)$ & (11.495) & (12.831) & (1.553) & $(27.640)$ & (30.881) \\
\hline $\mathrm{N}$ & 3,261 & 3,249 & 3,140 & 3,261 & 3,249 & 3,140 \\
\hline $\mathrm{F}$ & 26.687 & 22.272 & 19.984 & 28.764 & 25.060 & 21.857 \\
\hline r2 & 0.097 & 0.102 & 0.118 & 0.104 & 0.113 & 0.128 \\
\hline
\end{tabular}

Note: (1) The values in brackets are standard errors; (2) ***, and *** indicate significance at the confidence levels of $10 \%, 5 \%$, and $1 \%$, respectively.

the degree of enterprise management. In addition, the ratio of operating profit to the number of employees and the ratio of operating profit to total assets are used to explain the rate of return on labor and the rate of return on assets, respectively, which are used to measure the efficiency of the enterprise. The specific results are shown in Table 15. The regression results show that 
the CLCP policy implementation not only improves the management costs paid by enterprises but also enterprises efficiency. This shows that rational enterprises, under the constraint of environmental regulation, are more inclined to adopt methods of strengthening internal management and improving operating efficiency to manage the increase in production costs.

Table 15: The impact of the CLCP policy on enterprise management efficiency

\begin{tabular}{ccccccc}
\hline & \multicolumn{2}{c}{ managemcosts } & \multicolumn{2}{c}{ laborprofitratio } & \multicolumn{2}{c}{ capitalprofitratio } \\
& $\mathbf{( 1 )}$ & $\mathbf{( 2 )}$ & $\mathbf{( 3 )}$ & $\mathbf{( 4 )}$ & $\mathbf{( 5 )}$ & $\mathbf{( 6 )}$ \\
\hline Pilot $\times$ Time & $0.357^{* * *}$ & $0.653^{* * *}$ & $24.976^{* * *}$ & 1.923 & $0.102^{* * *}$ & $0.070^{* * *}$ \\
& $(0.004)$ & $(0.005)$ & $(1.365)$ & $(1.453)$ & $(0.003)$ & $(0.004)$ \\
Control variables & NO & YES & NO & YES & NO & YES \\
Individual fixed effects & YES & YES & YES & YES & YES & YES \\
Time fixed effects & YES & YES & YES & YES & YES & YES \\
_cons & $7.202^{* * *}$ & $1.737^{* * *}$ & $21.869^{* * *}$ & $-167.310^{* * *}$ & $0.079^{* * *}$ & $0.768^{* * *}$ \\
& $(0.004)$ & $(0.022)$ & $(1.212)$ & $(6.868)$ & $(0.003)$ & $(0.017)$ \\
N & 676257 & 600090 & 623489 & 600048 & 676149 & 600048 \\
F & 28283.599 & 26262.932 & 160.269 & 853.978 & 964.095 & 2394.486 \\
r2 & 0.389 & 0.492 & 0.004 & 0.031 & 0.021 & 0.081 \\
\hline
\end{tabular}

Note: (1) The values in brackets are standard errors; $(2) *$ **, and *** indicate significance at the confidence levels of $10 \%, 5 \%$, and $1 \%$, respectively.

\subsubsection{The impact of the CLCP policy on enterprise productivity}

Moreover, we examine enterprises productivity. On the premise of data availability, in order to comprehensively measure enterprises productivity, we respectively use methods of OLS and LP. Specific results are shown in Table 16. Columns (1)-(3) show the results of using OLS method to estimate enterprise productivity, while Columns (4)-(6) show the results of using LP method. Among them, Column (3) and Column (6) are mainly regression results of sample enterprises after 2005. As can be seen from Table 16, CLCP policy has significantly improved enterprises productivity. The result shows that environmental regulation can improve enterprises productivity, which fully supports "productivity improvement hypothesis".

\subsubsection{The impact of the CLCP policy on enterprise innovation}

In addition to strengthening management and improving operating efficiency, as a major innovation subject in the modern economic system, the innovation function of an enterprise can not be ignored. In view of this, this article also considers that enterprises engage in innovative activities in response to increased costs caused by environmental constraints. On the one hand, an 
Table 16: The impact of CLCP policy on enterprise productivity

\begin{tabular}{|c|c|c|c|c|c|c|}
\hline & \multicolumn{3}{|c|}{ TFP_OLS } & \multicolumn{3}{|c|}{ TFP_LP } \\
\hline & (1) & (2) & (3) & (4) & (5) & (6) \\
\hline \multirow[t]{2}{*}{ Pilot $\times$ Time } & $0.331 * * *$ & $0.129 * * *$ & $0.088 * * *$ & $85.919 * * *$ & $51.554 * * *$ & $51.554 * * *$ \\
\hline & $(0.004)$ & $(0.003)$ & $(0.003)$ & (3.494) & $(2.691)$ & $(2.691)$ \\
\hline Control variables & NO & YES & YES & NO & YES & YES \\
\hline Individual fixed effects & YES & YES & YES & YES & YES & YES \\
\hline Time fixed effects & YES & YES & YES & YES & YES & YES \\
\hline \multirow[t]{2}{*}{ _cons } & $-0.137 * * *$ & $3.053 * * *$ & $3.547 * * *$ & $293.706 * * *$ & $-748.442 * * *$ & $-748.442 * * *$ \\
\hline & $(0.003)$ & $(0.016)$ & $(0.023)$ & (3.103) & (12.720) & $(12.720)$ \\
\hline $\mathrm{N}$ & 623544 & 600147 & 391015 & 623544 & 600147 & 600147 \\
\hline $\mathrm{F}$ & 11611.306 & 15665.968 & 21506.183 & 3167.515 & 5145.222 & 5145.222 \\
\hline r2 & 0.210 & 0.366 & 0.488 & 0.068 & 0.160 & 0.160 \\
\hline
\end{tabular}

Note: (1) The values in brackets are standard errors; $(2) *, * *$, and *** indicate significance at the confidence levels of $10 \%, 5 \%$, and $1 \%$, respectively.

enterprise realizes the transformation of production products through innovation to win greater market competitiveness and gain more profits. On the other hand, through the innovation of clean production technology, enterprises can overcome the decline of benefits caused by the increase of costs and seek lasting impetus for their survival. In this regard, this study measures the innovation of enterprises by the logarithm of the output value of new products (newproduct) and the logarithm of the total export volume of enterprises (exportsize). At the same time, the relative value of innovation ability is measured by the proportion of new product output to the main business income (newproductrate). The specific results are shown in Columns (1)- (3) in Table 17. In addition, considering the interference of relevant policies, this analysis also excludes the year of investigation. The specific results are shown in Columns (4)- (6) in Table 17. The results show that the implementation of the CLCP policy promotes the innovation activities of enterprises, and the promotion effect is significant at the $1 \%$ confidence level. This conclusion shows that under environmental constraints, enterprises tend to choose innovation activities in the face of a significant increase in costs and to realize the maximization of enterprise earnings through innovation to avoid the negative impact of environmental regulations on enterprises. 
Table 17: The impact of the CLCP policy on enterprise innovation

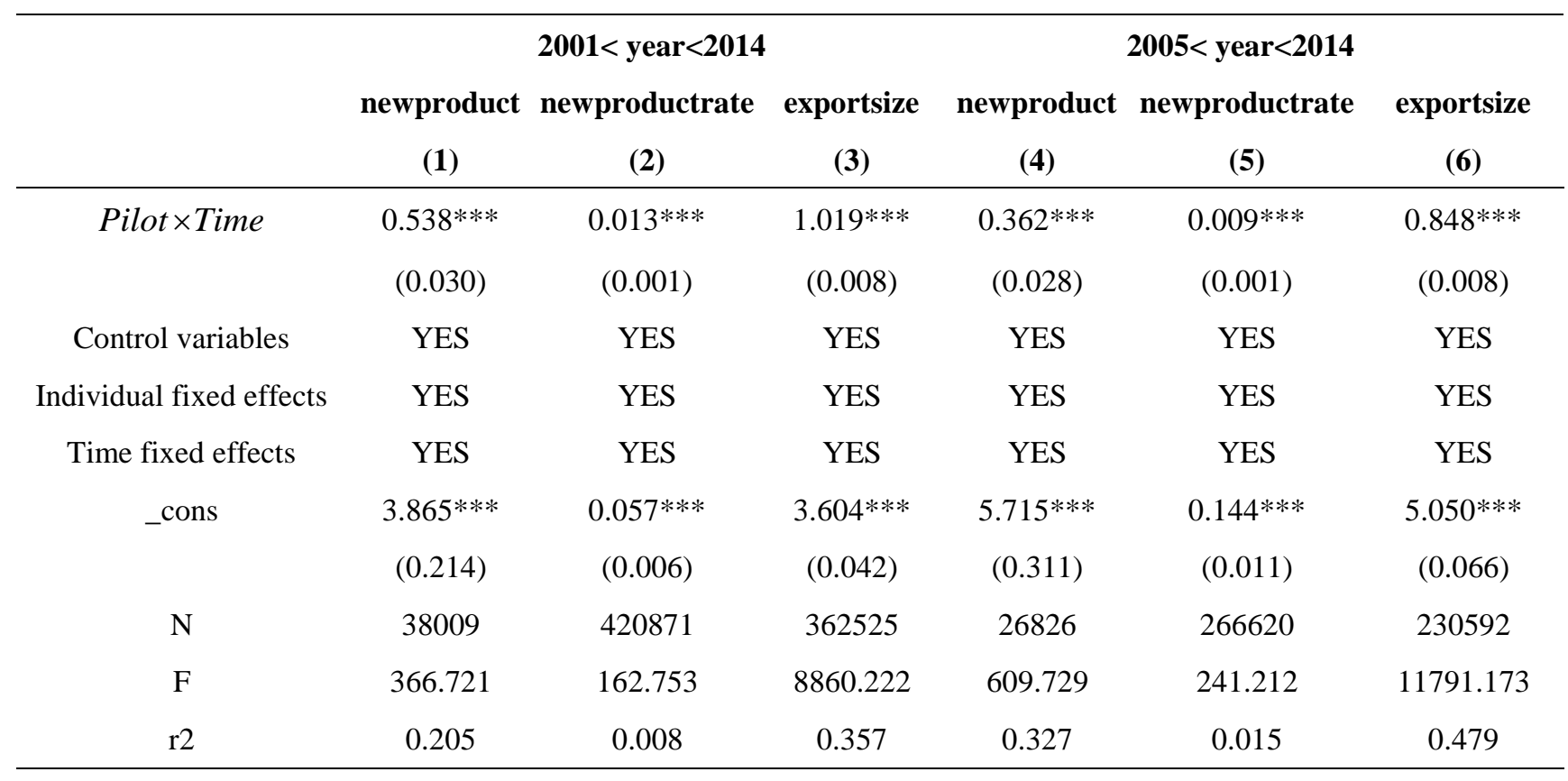

Note: (1) The values in brackets are standard errors; (2)*,**, and *** indicate significance at the confidence levels of $10 \%$, $5 \%$, and $1 \%$, respectively.

\section{Conclusions}

The global warming problem has become increasingly serious and is the focus of governments worldwide. Governments have introduced policies to reduce carbon emissions in response to climate change. As the world's largest emitter of carbon dioxide, China's economic development has also had a tremendously negative impact on global climate governance. In view of this, in the face of the reality of global warming, the Chinese government has the responsibility and obligation to actively participate in global climate governance and make efforts to reduce carbon emissions. The CLCP policy implementation is an important step for the Chinese government to fulfill its responsibilities, and it is also an important measure to respond to greenhouse gas emissions. An analysis of the economic benefits of the policy is beneficial for researchers and policy makers to fully understand the effects of environmental regulation, which has great practical significance for the Chinese government in promoting the policy nationally. Based on the panel data of Chinese prefecture-level cities and the micro data of Chinese industrial enterprises from 2001 to 2013, this article constructs a quasi-natural experiment by using the CLCP policy implementation in eight cities and five provinces. This article then evaluates the impact of environmental regulations on local economic growth and enterprise behavior, and makes clear inferences about the causality between environmental regulation and economic growth by using the DID method. 
The results show that the CLCP policy implementation significantly promotes the economic growth of local cities. At the same time, the dynamic effect test shows that environmental regulation has a long-term promoting effect on economic growth, but there is a significant timelag. According to the analysis of micro enterprises, it can be seen that although the CLCP policy implementation can increase the production costs, it also significantly promotes the output and income of enterprises. Instead of exiting from the market, enterprises deal with the increased costs in a more proactive way. On the one hand, enterprises constantly strengthen internal management and improve productivity; on the other hand, enterprises constantly input more resources to conduct innovative activities to overcome cost increase and to realize the improvement of enterprise income. The root cause of environmental regulation to promote economic growth lies in the change of enterprise behavior, which provides a good explanation for the economic benefits of the CLCP policy implementation. The research conclusion of this article shows that environmental regulation and economic development can achieve a "winwin" situation and fundamentally revises the traditional concept that environmental regulation restrains economic growth, that is, economic growth is bound to be at the expense of the environment. The results show that the government can achieve the rapid growth of a regional economy while implementing environmental regulation.

The conclusions of this article provide strong theoretical support and a practical foundation for the environmental distress and economic structural transformation faced by developing countries. The specific policy implications are as follows. First, in the face of deteriorating environmental pressures, governments should abandon the traditional misconceptions and attempt to improve environmental governance, thereby achieving economic growth. Second, it is found that environmental regulation has a long-term role in local economic growth, but there is a time-lag. This conclusion suggests that the government should pay considerable attention to the long-term effectiveness of policies and not merely only focus on the short-term benefits. Third, when economic development enters a transition period, how to realize the transfer of industries with high energy consumption, pollution and emissions is the key issue faced by local governments. The results of this article show that environmental regulation can be used to measure the impact of various industries on the environment. According to this, governments can construct environmentally friendly industrial structures suitable for green development. Therefore, environmental regulation is a powerful tool for economic structural transformation to thus further promote regional environmental governance and economic development. Fourth, considering the changes of enterprises' behavior in the process of environmental regulation, the government should subsidize enterprise innovation, encourage internal adjustment and productivity improvement and restrict trans-regional transfers, thereby resolving the dilemma of local environmental governance and overall environmental degradation. Thus, the environmental regulation represented by the CLCP policy implementation provides a feasible path for more developing countries to choose low-carbon green development, makes it possible to further realize a "win-win" situation between environmental governance and economic development, creates opportunities to explore new ways of economic development, and provides useful experience for developing countries to seek environmental governance and develop sustainable roads.

Acknowledgments The authors gratefully acknowledge the financial support from the National Social Science Foundation of China (No.16BZZ086), Incubation Program on The National Social Science Fund in 2020 of 
Northwest University of China (No. 20XNZX004), as well as National Social Science Youth Foundation of China (No. 16CJL014)

\section{References}

Aghion, P., Dechezleprêtre, A., Hémous, D., Martin, R., and Van, R.J. (2016). Carbon taxes, path dependency, and directed technical change: Evidence from the auto industry. Journal of Political Economy 124(1), 1-51. https://www.journals.uchicago.edu/doi/abs/10.1086/684581

Alfaro, L., Chanda, A., Kalemli-Ozcan, S., and Sayekd, S. (2002). FDI and economic growth: the role of local financial markets. Journal of International Economics 64(1), 89-112. https://www.sciencedirect.com/science/article/abs/pii/S0022199603000813

Anderson, D. (1990). Investment and economic growth. World Development 18(8), 1057-1079. https://www.sciencedirect.com/science/article/pii/0305750X9090088F

Anderson, B., and Di Maria, C. (2011). Abatement and allocation in the pilot phase of the EU ETS. Environmental and Resource Economics 48(1), 83-103. https://link.springer.com/article/10.1007/s10640-010-9399-9

Berthélemy, J.C., and Démurger, S. (2000). Foreign direct investment and economic growth: theory and application to China. Review of Development Economics 4(2), 140-155. https://onlinelibrary.wiley.com/doi/pdf/10.1111/1467-9361.00083

Böcher, M. (2012). A theoretical framework for explaining the choice of instruments in environmental policy. Forest Policy and Economics 16, 14-22.

https://www.sciencedirect.com/science/article/pii/S1389934111000311

Brunnermeier, S.B., and Cohen, M.A. (2003). Determinants of environmental innovation in US manufacturing industries. Journal of Environmental Economics and Management 45(2), 278-293. https://www.sciencedirect.com/science/article/abs/pii/S009506960200058X

Christainsen, G.B., and Haveman, R.H. (1981). Public regulations and the slowdown in productivity growth. The American Economic Review 71(2), 320-325. https://www.jstor.org/stable/1815738

Dai, R., and Cao, J.H. (2015). Evaluation of the carbon reduction effect of China's first "low-carbon pilot” policy -- based on DID estimation in eight cities and five provinces. Technology Management Research 35, 56-61. (In Chinese).

Ederington, J. and Minier, J. (2003). Is environmental policy a secondary trade barrier? An empirical analysis. Canadian Journal of Economics 36(1), 137-154.

https://onlinelibrary.wiley.com/doi/abs/10.1111/1540-5982.00007

Feng, C., Shi, B., and Kang, R. (2017). Does environmental policy reduce enterprise innovation? Evidence from China. Sustainability 9(6), 1-24. https://ideas.repec.org/a/gam/jsusta/v9y2017i6p872-d99388.html

Gagelmann, F., and Frondel, M. (2005). The impact of emission trading on innovation-science fiction or reality? European Environment 15(4), 203-211.

https://onlinelibrary.wiley.com/doi/abs/10.1002/eet.387 
Gray, W.B. (1987). The cost of regulation: OSHA, EPA and the productivity slowdown. American Economic Review 77(5), 998-1006. https://www.jstor.org/stable/1810223

Gray, W.B., and Shadbegian, R.J. (2003). Plant vintage, technology, and environmental regulation. Journal of Environmental Economics \& Management 46(3), 384-402. https://www.sciencedirect.com/science/article/abs/pii/S0095069603000317

Grubb, M., Azar, C., and Persson, U.M. (2005). Allowance allocation in the European emissions trading system: a commentary. Climate Policy 5(1), 127-136. https://www.tandfonline.com/doi/abs/10.1080/14693062.2005.9685545

Hamamoto, M. (2006). Environmental regulation and the productivity of Japanese manufacturing industries. Resource \& Energy Economics 28(4), 299-312. https://www.sciencedirect.com/science/article/abs/pii/S092876550600011X

Hamberg, D. (1969). Saving and economic growth. Economic Development \& Cultural Change 17(4), 211-218.

Hering, L., and Poncet, S. (2014). Environmental policy and exports: Evidence from Chinese cities. Journal of Environmental Economics and Management 68(2), 296-318. https://www.sciencedirect.com/science/article/abs/pii/S0095069614000394

Hoffmann, V.H. (2007). EU ETS and investment decisions: The case of the German electricity industry. European Management Journal 25(6), 464-474. https://www.sciencedirect.com/science/article/abs/pii/S0263237307000837

Hondroyiannis, G., and Papapetrou, E. (2001). Demographic changes, labor effort and economic growth: empirical evidence from Greece. Journal of Policy Modeling 23(2), 169-188. https://www.sciencedirect.com/science/article/pii/S0161893800000375

Huang, Q.H., and Gao, M. (2016). The effect of environmental regulation on the quantity and quality of economic growth - a test based on simultaneous equations. Economist, 4, 53-62. (In Chinese).

Jefferson, G.H., Tanaka, S., and Yin, W. (2013). Environmental regulation and industrial performance: Evidence from unexpected externalities in China. (February 1, 2013).

https://papers.ssrn.com/sol3/papers.cfm?abstract_id=2216220

Jia, Z., Chen, X.P., and Shan, X.X. (2013). The implementation path of low-carbon transformation of industrial departments in pilot provinces - taking Shaanxi province as an example. Soft Science 27, 85-89. (In Chinese).

Jiang, S.Y., and Novák, M. (2004). Incentives for energy efficiency and innovation in the European Emission Trading System. Osteuropa 11, 267-273.

Johnstone, N., Haščič, I. and Popp, D. (2010). Renewable energy policies and technological innovation: evidence based on patent counts. Environmental and Resource Economics 4(1)5, 133-155. https://ink.springer.com/article/10.1007/s10640-009-9309-1

Landau, D. (1986). Government and economic growth in the less developed countries: An empirical study for 1960-1980. Economic Development \& Cultural Change, 35(1), 35-75. https://www.jstor.org/stable/1154144 
Mazzanti, M., and Zoboli, R. (2009). Environmental efficiency and labor productivity: Trade-off or joint dynamics? A theoretical investigation and empirical evidence from Italy using NAMEA. Ecological Economics 68(4), 1182-1194.

https://www.sciencedirect.com/science/article/pii/S0921800908003856

Mello, M. (2008). Skilled labor, unskilled labor, and economic growth. Economics Letters 100(3), 428431. https://www.sciencedirect.com/science/article/abs/pii/S0165176508000955

Moreno-Brid, J.C., Santamaría, J., and Valdivia, J.C.R. (2005). Industrialization and economic growth in Mexico after NAFTA: The road travelled. Development and Change 36(6), 1095-1119. https://onlinelibrary.wiley.com/doi/abs/10.1111/j.0012-155X.2005.00451.x

Moser, P., and Voena, A. (2012). Compulsory licensing: Evidence from the trading with the Enemy Act. American Economic Review 102(1), 396-427. https://www.jstor.org/stable/41408779

Pickman, H. A. (1998). The effect of environmental regulation on environmental innovation. Business Strategy \& the Environment 7(4), 223-233. https://onlinelibrary.wiley.com/doi/abs/10.1002/\%28SICI\%2910990836\%28199809\%297\%3A4\%3C223\%3A\%3AAID-BSE164\%3E3.0.CO\%3B2-S

Porter, M.E., and van der Linde, C.V.D. (1995). Toward a new conception of the environmentcompetitiveness relationship. Journal of Economic Perspectives 9(4), 97-118. https://www.jstor.org/stable/2138392

Shi, B., Feng, C., Qiu, M., and Ekeland, A. (2018). Innovation suppression and migration effect: The unintentional consequences of environmental regulation. China Economic Review, 49, 1-23. https://ideas.repec.org/a/eee/chieco/v49y2018icp1-23.html

Stavins, R.N. (2008). A meaningful US cap-and-trade system to address global climate change. Climate Change Modelling and Policy Working Papers 44469, Fondazione Eni Enrico Mattei (FEEM). https://ideas.repec.org/p/ags/feemcc/44469.html

Taylor, M.R. (2012). Innovation under cap-and-trade programs. Proceedings of the National Academy of Sciences 109(13), 4804-4809. https://www.pnas.org/content/109/13/4804

Tomás, R.A.F., Ramôa, F.R., Santos, V.M.S., Gomes, J.F.P., and Bordado, J.C.M. (2010). Assessment of the impact of the European CO2 emissions trading scheme on the Portuguese chemical industry. Energy Policy 38(1), 626-632.

https://www.sciencedirect.com/science/article/pii/S0301421509004819

Wang, M., and Huang, Y. (2015). China's environmental pollution and economic growth. Economic Quarterly 1, 557-578. (In Chinese).

Xie, J., Li, Y.S., and Han, F. (2012). Environmental regulation and economic growth: an analysis based on the simultaneous equations of interprovincial panels in China. Economic Survey 5, 1-5. (In Chinese).

Xue, B., Lu, C.Y., Geng, Y., Liu Z., Zhang W.W., and Li, C.R. (2012). Review and prospect of China's low-carbon city pilot program. Economic Geography 32, 51-56. (In Chinese).

Yuan, Y.J., and Liu, L. (2013). Environmental regulation and economic growth: A study based on the classification of economic regulation. Economic Review 1, 27-33. (In Chinese). 
Zhao, X. W. (2014). Environmental regulation, environmental regulation competition and regional industrial economic growth - an empirical study based on spatial Durbin panel model. Journal of International Trade 7, 82-92. (In Chinese). 


\section{Economics}

Please note:

You are most sincerely encouraged to participate in the open assessment of this article. You can do so by either recommending the article or by posting your comments.

Please go to:

http://dx.doi.org/10.5018/economics-ejournal.ja.2019-47

The Editor 